


\title{
Consumption Insurance Against Wage Risk: Family Labor Supply and Optimal Progressive Income Taxation*
}

\author{
Chunzan $\mathrm{Wu}$ \\ University of Miami
}

\author{
Dirk Krueger \\ University of Pennsylvania, \\ CEPR, CFS, NBER and Netspar
}

September 22, 2019

\begin{abstract}
We show that a calibrated life-cycle two-earner household model with endogenous labor supply can rationalize the extent of consumption insurance against shocks to male and female wages, as estimated empirically by Blundell, Pistaferri, and Saporta-Eksten (2016) in U.S. data. In the model, $35 \%$ of male and $18 \%$ of female permanent wage shocks pass through to consumption, compared to the empirical estimates of $32 \%$ and $19 \%$. Most of the consumption insurance against permanent male wage shocks is provided through the presence and labor supply response of the female earner. Abstracting from this private intra-household income insurance mechanism strongly biases upward the welfare losses from idiosyncratic wage risk as well as the desired extent of public insurance through progressive income taxation. Relative to the standard one-earner life cycle model, the optimal degree of tax progressivity is significantly lower and the welfare gains from implementing the optimal system are cut roughly in half.
\end{abstract}

${ }^{*}$ We thank Greg Kaplan and Luigi Pistaferri for useful conversations at an early stage of this project, as well as Itay Saporta-Eksten for providing important details about the implementation of the BPS method. Krueger gratefully acknowledges financial support from the NSF under grant SES-0820494. 


\section{Introduction}

How does household consumption respond to shocks to wages of the primary earner? The baseline version of the permanent income hypothesis in which a household has only one bread winner with exogenous labor supply provides a sharp answer: household consumption responds to permanent wage shocks one for one, and essentially not at all to purely transitory shocks. In a sequence of influential papers, Blundell, Pistaferri, and Preston (2008) and Kaplan and Violante (2010) measure the magnitude of the household consumption response to earnings shocks with given persistence by consumption insurance coefficients, defined as the fraction of the variance of the shock that does not translate into a corresponding change in log-consumption. ${ }^{1}$ That is, if the consumption insurance coefficient for a given earnings shock is one, household consumption growth is completely insulated from the earnings shock, and if it is zero, the earnings shock translates one for one into consumption growth. Blundell, Pistaferri, and Preston (2008) empirically estimate these consumption responses to transitory and permanent earnings shocks on U.S. data and find close to perfect insurance against purely transitory shocks (except for poor households), as well as substantial insurance against permanent shocks, with a consumption insurance coefficient of $35 \% .^{2}$ Kaplan and Violante (2010) evaluate whether a calibrated single-earner incomplete-markets life cycle model with transitory and permanent earnings shocks is consistent with the empirical estimates of Blundell, Pistaferri, and Preston (2008). They find that in the model households are close to fully insured against transitory earnings shocks, but that there is too little consumption insurance against permanent shocks: the model-implied consumption insurance coefficient ranges between $7 \%$ and $22 \%$, depending on the tightness of the borrowing constraints.

\footnotetext{
${ }^{1}$ Formally, denote by $c_{i t}$ the log of consumption of household $i$ at time or age $t$, and define the consumption insurance coefficient for earnings shock $x_{i t}^{n}$ of type $n$ as

$$
\phi_{t}^{n}=1-\frac{\operatorname{Cov}_{i}\left(\Delta c_{i t}, x_{i t}^{n}\right)}{\operatorname{Var}_{i}\left(x_{i t}^{n}\right)},
$$

where $\operatorname{Cov}_{i}, \operatorname{Var}_{i}$ are the cross-sectional (co-)variances across households $i$ at time (age) $t$.

${ }^{2}$ Also see Santaeulàlia-Llopis and Zheng (2018) for a recent application of the same method to Chinese data.
} 
In Blundell, Pistaferri, and Preston (2008) and Kaplan and Violante (2010), household earnings are treated as exogenous, and the key mechanism through which consumption insurance is achieved is asset accumulation. This literature is therefore silent about the underlying shocks behind earnings fluctuations, as well as the alternative mechanisms through which households respond to these underlying shocks. The current paper instead models the fundamental sources of consumption risk as idiosyncratic shocks (of various persistence) to wages of the male and female earners in an otherwise standard incomplete-markets economy with twomember households. In this paper we seek to make three contributions. Our first contribution is to quantify the extent to which wage shocks translate into consumption movements, and to evaluate the relative importance of alternative mechanisms (adjustment of labor hours of both household members, and participation of the female earner, as well as precautionary savings and progressive income taxation and social security) by which consumption insurance occurs in the model.

Second, we assess whether the standard Bewley model with endogenous labor supply of two-earner households can match well the empirically estimated labor supply and consumption responses to transitory and permanent wage shocks, as derived in the important recent paper by Blundell, Pistaferri, and Saporta-Eksten (2016), henceforth BPS. ${ }^{3}$ In this work, which is the natural extension of Blundell, Pistaferri, and Preston (2008) to endogenous household labor supply choices, the authors empirically estimate the transmission coefficients from transitory and permanent wage shocks to labor earnings and consumption in two-earner (male and female) households. ${ }^{4}$ Our findings suggest that a standard Bewley model with twoearner households and endogenous labor supply can explain virtually all of the insurance of household consumption and labor income to wage shocks estimated by BPS. This is in contrast to Kaplan and Violante (2010) who concluded that, treating income as exogenous, the standard Bewley model predicts significantly too little consumption insurance against permanent income shocks. In our calibrated model

\footnotetext{
${ }^{3}$ In Blundell, Pistaferri, and Saporta-Eksten (2018), the authors extend their analysis to a model with children; we discuss this paper in greater detail below.

${ }^{4}$ For consumption, their transmission coefficients have exactly the same interpretation as the consumption insurance coefficients discussed above, but are now understood as measuring the degree of consumption insurance against wage rather than earnings shocks. With single-earner households and exogenous labor supply the two coincide exactly.
} 
with additively separable preferences between consumption and labor supply, about $35 \%$ of male permanent wage shocks and $18 \%$ of female permanent wage shocks pass through to household consumption. The corresponding empirical estimates of BPS are $32 \%$ and $19 \%$, respectively. The insurance against transitory wage shocks is almost perfect in the model with close-to-zero pass-through rates for both male and female shocks, while the BPS data counterparts are slightly negative, but economically and statistically close to zero. In addition, both the model and the empirical BPS results indicate that consumption insurance against permanent wage shocks improves over the life cycle, in the model caused by an improved asset position as households age. ${ }^{5}$ A decomposition of consumption insurance against male permanent wage shocks in the model shows that the presence and labor supply response of the female member of the household account for most of this insurance, with a contribution that is almost constant over the life cycle. In contrast, the contribution of male labor supply is negative (that is, male hours fall in response to a permanent negative male wage shock), increasingly so over the life cycle.

Motivated by this last result concerning the importance for consumption insurance of the secondary earner, as our third contribution we demonstrate that the welfare losses from idiosyncratic wage risk, and the desired social insurance via progressive income taxes, are significantly overstated when this private household insurance mechanism is not accounted for. Relative to the standard one-earner life cycle model, the overall welfare cost from idiosyncratic wage risk is reduced by $35 \%$ (15.0\% instead of $23.2 \%$, measured as consumption equivalent variation). Finally, the optimal ${ }^{6}$ degree of tax progressivity is significantly lower and the welfare

\footnotetext{
${ }^{5}$ In the paper we also evaluate the empirical approach of BPS using model-simulated data. The estimation equations BPS employ are derived from a theoretical model with endogenous labor supply and incomplete asset markets and require interior solutions of the household maximization problem, which is not assured in a model with potentially binding borrowing constraints or an operative extensive margin of female labor supply. However, we show that the performance of the BPS estimator is not affected strongly by the violation of these assumptions as long as one restricts attention to households aged 30 to 57 , as they (and we) do. Most households in this age are no longer impacted by even a tight borrowing constraint (as they have accumulated away from it). The extensive labor supply margin induces relatively larger biases in the estimates related to female labor supply, but the impact of this model feature is limited, because the female non-participation rate is only moderate, both in our simulated data as well as in the original BPS data set.

${ }^{6}$ Optimality is defined as maximizing expected lifetime utility of a given cohort of households, with all policy reforms required to be revenue-neutral.
} 
gains from implementing the optimal system are cut in half in the two-earner model with endogenous family labor supply adjustments, suggesting that modeling this margin of adjustment explicitly is of first-order importance for the evaluation of social insurance polices.

Abstracting from the papers by Blundell, Pistaferri, and Preston (2008), Kaplan and Violante (2010), and Blundell, Pistaferri, and Saporta-Eksten (2016) that directly motivate this study, our work is related to the broader literature that has studied heterogeneous household models with idiosyncratic risks, as pioneered in Bewley (1986), Imrohoroğlu (1989), Huggett (1993), and Aiyagari (1994). The structural life cycle model we employ is most closely related to the models analyzed by Heathcote, Storesletten, and Violante (2010), Holter, Krueger, and Stepanchuk (2019), and Park and Shin (2019). However, their applications mainly focus on inequality and fiscal policy rather than the private consumption insurance question we address here. As we do, Karahan and Ozkan (2013) measure the welfare cost of idiosyncratic earnings risk, but do not endogenize labor supply of the household. Heathcote, Storesletten, and Violante (2014) study consumption insurance against wage shocks in an economy populated by single households making endogenous labor supply decisions and having access to within-group risk-sharing arrangements, but they abstract from the insurance provided by a second earner in the household. Finally, perhaps closest to this paper is the study by Blundell, Pistaferri, and Saporta-Eksten (2018). In their structural model, households also choose family labor supply (along the intensive and extensive margin) and time spent with children. Their main focus is on how consumption insurance is impacted by the presence of children in the household, and how public income transfers to families with children change this impact. They do not consider the analysis of (optimal) progressive income taxation in the presence of private consumption insurance through spousal labor supply, one main focus of our work

The paper is also related to the literature on within-household risk-sharing and the role female labor supply plays in this context. For example, Attanasio, Low, and Sánchez-Marcos (2005) study the importance of female labor supply as an insurance mechanism against idiosyncratic income risk within the family, but in their model the labor supply decision is discrete and the intensive margin of labor supply 
is absent. Ortigueira and Siassi (2013) investigate the impact of within-household risk-sharing on household labor supply and savings. However, only idiosyncratic unemployment risk is considered and there is no life cycle in their model.

The rest of this paper proceeds as follows: Section 2 sets up the model, and Section 3 discusses its calibration. Section 4 reports our main positive results, with main focus on the consumption insurance against wage risk in the model and the relevant mechanisms to achieve that insurance. It also provides an assessment of the potential bias of the BPS estimates. In Section 5, we turn to the normative evaluation of wage risk and the optimal degree of progressive taxation against that risk. Section 6 provides a sensitivity analysis with respect to the tightness of borrowing constraints and the separability of household utility between consumption and labor supply of both spouses, and Section 7 concludes. The appendix contains supplementary results as well as the implementation of the BPS methodology.

\section{The Model}

In this section, we first describe the physical environment of our model, and then state the household maximization in recursive formulation.

\subsection{Environment}

We study a partial equilibrium life cycle model with idiosyncratic wage risk and endogenous household labor supply. We follow a cohort of a continuum of measure one households over their life cycle. These households live for $T$ periods, from age $t=1$ to $T$, work in the first $R$ periods of life, and then are retired from age $R+1$ onward. Each household has two members of equal age: a male and a female. Generically, we denote by $X_{j, t}$ the variable $X$ of earner $j \in\{1,2\}$ at age $t$, with $j=1(j=2)$ indicating the male (female) member of the household.

In each period, households receive utility from joint household consumption, $C_{t}$. A working household's utility is also affected by the levels of their labor supply, $H_{1, t}$ and $H_{2, t}$. Hence the period utility function is assumed to be $u\left(C_{t}, H_{1, t}, H_{2, t}\right)$ for a working household and $u^{R}\left(C_{t}\right)$ for a retired household. Given the fact that a significant proportion of females do not participate in the labor market, an operative extensive margin of female labor supply is included in the model by introducing a fixed per-period utility cost $f$ whenever female hours worked is strictly positive. 
Households discount the future utility at the constant rate $\delta$, so that $1 /(1+\delta)$ is the household time discount factor.

The two members of each household are assumed to make joint decisions on consumption and labor supply. Members of a household can work at wages $W_{j, t}$ determined by their labor productivity. Log-wages of both household members are stochastic and represent the sum of a deterministic life cycle component $g_{j, t}$, a transitory component $u_{j, t}$, and a permanent component $F_{j, t}$ :

$$
\begin{aligned}
\ln W_{j, t} & =g_{j, t}+F_{j, t}+u_{j, t}, \\
F_{j, t} & =F_{j, t-1}+v_{j, t}, \\
{\left[\begin{array}{l}
v_{1, t} \\
v_{2, t}
\end{array}\right] } & \sim \text { iid } N\left(0,\left[\begin{array}{cc}
\sigma_{v_{1}}^{2} & \sigma_{v_{1}, v_{2}} \\
\sigma_{v_{1}, v_{2}} & \sigma_{v_{2}}^{2}
\end{array}\right]\right), \\
{\left[\begin{array}{l}
u_{1, t} \\
u_{2, t}
\end{array}\right] } & \sim \operatorname{iid} N\left(0,\left[\begin{array}{cc}
\sigma_{u_{1}}^{2} & \sigma_{u_{1}, u_{2}} \\
\sigma_{u_{1}, u_{2}} & \sigma_{u_{2}}^{2}
\end{array}\right]\right) .
\end{aligned}
$$

Hence $v_{j, t}$, is the permanent shock to earner $j$ 's wage, and $u_{j, t}$ is the transitory shock. Both $v_{j, t}$ and $u_{j, t}$ can be correlated across the two members of each household, but are assumed to be independent between each other and over time. After retirement, labor productivity falls to zero, and hence households optimally do not work in retirement. A retired household receives a fixed amount of social security benefits, $b$, in each period in which she is alive.

As is common in standard incomplete-markets models, households cannot trade fully state-contingent Arrow securities, but they can save, and potentially borrow, at the risk-free interest rate $r$. They are, however, subject to age-dependent and potentially binding borrowing constraints $\underline{A}_{t}$.

\subsection{Household Optimization Problem}

A working household's problem can be written in recursive form as:

$$
\begin{gathered}
V\left(A, F_{1}, F_{2}, u_{1}, u_{2}, t\right)=\max _{C, A^{\prime}, H_{1}, H_{2}} u\left(C, H_{1}, H_{2}\right)-\mathbf{I}\left(H_{2}>0\right) f \\
+\frac{1}{1+\delta} \sum_{\left(F_{1}^{\prime}, F_{2}^{\prime}\right)} \pi\left(F_{1}^{\prime}, F_{2}^{\prime} \mid F_{1}, F_{2}\right) \sum_{\left(u_{1}^{\prime}, u_{2}^{\prime}\right)} \pi\left(u_{1}^{\prime}, u_{2}^{\prime}\right) V\left(A^{\prime}, F_{1}^{\prime}, F_{2}^{\prime}, u_{1}^{\prime}, u_{2}^{\prime}, t+1\right) \\
\text { s.t. } \quad C+A^{\prime}=Y-\widetilde{T}(Y)-\tau_{s s} Y+(1+r) A, \\
\quad Y=W_{1, t} H_{1}+W_{2, t} H_{2},
\end{gathered}
$$




$$
C, H_{1}, H_{2} \geq 0, A^{\prime} \geq \underline{A}_{t+1},
$$

where $\pi(\cdot \mid \cdot)$ governs the transition probabilities of the wage shocks, ${ }^{7}$ and $\mathbf{I}\left(H_{2}>0\right)$ equals 1 if female hours $H_{2}$ is positive. Female hours of $H_{2}=0$ corresponds to non-participation. The term $\widetilde{T}(Y)$ is the income tax function that determines the tax liability of a household with before-tax income $Y$, and $\tau_{s s}$ is a flat payroll tax representing the Social Security and Medicare taxes. The dynamic programming problem of a retired household is given by:

$$
\begin{aligned}
V^{R}(A, t) & =\max _{C, A^{\prime}} u^{R}(C)+\frac{1}{1+\delta} V^{R}\left(A^{\prime}, t+1\right) \\
\text { s.t. } & C+A^{\prime}=b+(1+r) A, \\
& C \geq 0, A^{\prime} \geq \underline{A}_{t+1} .
\end{aligned}
$$

When in working age, the household has an additively separable utility function of the form:

$$
u\left(C, H_{1}, H_{2}\right)=\frac{C^{1-\sigma}}{1-\sigma}-\psi_{1} \frac{H_{1}^{1+\eta_{1}^{-1}}}{1+\eta_{1}^{-1}}-\psi_{2} \frac{H_{2}^{1+\eta_{2}^{-1}}}{1+\eta_{2}^{-1}},
$$

where the parameter $\sigma$ governs the intertemporal elasticity of substitution for consumption, and its reciprocal is the Frisch elasticity of consumption with respect to its own price. The parameters $\eta_{1}$ and $\eta_{2}$ are the Frisch elasticities of male and female labor supply with respect to their own wages. The key advantage of using this preference structure is that the intertemporal and Frisch labor supply elasticities are exclusively determined by exogenous parameters which are therefore directly interpretable. In Section 6.2, we explore the robustness of our results to using a non-separable utility specification that is more flexible in terms of substitution patterns between consumption and hours worked of both spouses. The period utility function for a retired household is given by

$$
u^{R}(C)=u(C, 0,0)=\frac{C^{1-\sigma}}{1-\sigma} .
$$

\footnotetext{
${ }^{7}$ Since we will discretize the support of the wage shocks when computing the model, we represent the conditional expectation in the dynamic programming problem as a sum, rather than an integral.
} 


\section{Calibration}

In this section, we describe how we parameterize the model, using empirical targets derived from U.S. household data, as measured in the PSID.

\subsection{Data}

In BPS, the data used are from the 1999 to 2009 waves of the Panel Study of Income Dynamics (PSID). The PSID collects data from two groups of households: one group representative of the U.S. population, the other from low-income households in the Survey of Economic Opportunity (SEO). BPS' estimation uses only data from non-SEO households with male household heads aged between 30 and 57 that are married and participate in the labor market. Because one goal of our study is to compare the degree of consumption insurance implied by our model to the empirical BPS estimates, the model is calibrated to match the statistics from precisely this group of households, whenever possible. This calibration strategy gives the best chance to the model of fitting the BPS estimates. Consequently, if we still find significant differences between our model and the BPS empirical results, they are likely caused by model mis-specification rather than inappropriate parameter values.

\subsection{Demographic and Initial Conditions}

Households are born at age 21 , retire at age 65 , and die at age 80 . Therefore, age 1 in the model corresponds to age 21 in the data, and consequently $R=45$ and $T=60$. Households start their life with zero assets and a permanent and transitory components of log-wages equal to zero. ${ }^{8}$

\footnotetext{
${ }^{8}$ The median age at first marriage in the U.S. between 2000 and 2010 is 27.5 for males and 26 for females, according to U.S. Census data. The starting age of 21 of married households in the model is therefore younger than in the data. There are mainly two reasons why we made this choice. First, the initial age at which a couple starts cohabitating and thus sharing wage risk is likely much younger than that of eventual marriage. Second, at the time of official marriage couples have already accumulated some assets, and have permanent wage components determined by previously realized sequences of shocks. It is difficult to empirically identify the permanent components of wages at individual level, and thus problematic to measure an exact empirical joint distribution of the permanent wage components and asset level (the initial states of simulated households). Thus, as an imperfect compromise, we assume that the life cycle of a household begins at an earlier age with zero assets. When calculating the relevant model statistics, only simulated data from households of ages 30 to 57 are used (the same age group employed by BPS), and therefore the exact choice of
} 


\subsection{Wage Process}

The deterministic life cycle profile of wages is taken directly from the paper by Rupert and Zanella (2015). They estimate this wage profile on PSID data from 1967-2008. The original wage profile starts from age 23 and has only biennial values after age 52 . Therefore, we interpolate their profiles to annual observations and extend the age range to 21-65. Because Rupert and Zanella (2015) report only a pooled wage profile for males and females, and the estimation of female wage profile often suffers from the selection bias from females' participation decisions, in the model we assume that deterministic life cycle wage profiles of male and female earners have the same shape over the life cycle, but different levels. ${ }^{9}$ The life cycle average of the male wage trend is normalized to be 1. In the BPS data, average annual earnings of working females is 0.491 times that of males; we calibrate the level of female wages to match this earnings ratio. ${ }^{10}$

Turning to the stochastic component of wages, the covariance matrices of transitory and permanent wage shocks are taken directly from the BPS estimates. As in their work, both the permanent and transitory wage shocks are assumed to be iid across time but potentially positively correlated between the two earners of a household:

$$
\begin{aligned}
& {\left[\begin{array}{cc}
\sigma_{u_{1}}^{2} & \sigma_{u_{1}, u_{2}} \\
\sigma_{u_{1}, u_{2}} & \sigma_{u_{2}}^{2}
\end{array}\right]=\left[\begin{array}{ll}
0.0275 & 0.0058 \\
0.0058 & 0.0125
\end{array}\right],} \\
& {\left[\begin{array}{cc}
\sigma_{v_{1}}^{2} & \sigma_{v_{1}, v_{2}} \\
\sigma_{v_{1}, v_{2}} & \sigma_{v_{2}}^{2}
\end{array}\right]=\left[\begin{array}{ll}
0.0303 & 0.0027 \\
0.0027 & 0.0382
\end{array}\right] .}
\end{aligned}
$$

\subsection{Borrowing Limit}

Since the tightness of the borrowing limit is an important determinant of consumption smoothing opportunities, especially early in life, we calibrate it such that

initial conditions for the model is not critical for our results.

${ }^{9}$ Since the deterministic wage trends are perfectly predictable by households in the model, the behavioral response of households with respect to wage shocks, the main focus of this paper, is not significantly affected by the precise life cycle profile of the deterministic wage component.

${ }^{10}$ One unit of income in the model represents $\$ 61597$ in 2000 dollars, which is the average male labor income for age 30-57 households in the BPS data set. This number is slightly different from the one reported in Table 1 of BPS because BPS report the average of nominal income without adjusting for inflation. 
the model matches the debt-to-income ratio of young households in the data. In particular, we set the borrowing limit as $\underline{A}_{1}=\underline{A}, \underline{A}_{t+1}=(1+r) \underline{A}_{t}$ if $1 \leq t \leq T-1$, and $\underline{A}_{T+1}=0$ such that households can borrow up to a limit $\underline{A}$ at age 21 and can roll over that debt (at the fixed interest rate $r$ ) until the end of life $T$. The value for $\underline{A}$ is calibrated such that the median debt-to-income ratio of households aged 21-30, conditional on having any debt, in the model matches its counterpart in the extended BPS data set, which is $16.3 \% .^{11}$

\subsection{Discount Factor and Interest Rate}

We adopt BPS' choice of the real risk-free interest rate of $r=2 \%$ per year. The discount rate $\delta$, a key determinant of household precautionary (and life cycle) saving is calibrated such that the average net worth for households aged 30 to 57 in the model equals 4.188 times average male labor income, as measured in the BPS data set. This delivers a time discount rate of $0.5 \%$ per annum.

\subsection{Income Tax Function}

We permit the labor income tax function $T(Y)$ to be progressive, and following Bénabou (2002), use a two-parameter tax function (also employed by BPS) of the form:

$$
\widetilde{T}(Y)=Y-(1-\chi) Y^{1-\mu},
$$

where $\mu$ and $\chi$ are two parameters governing the progressivity and the level of the income tax, respectively. It implies that after-tax labor income $Y-\widetilde{T}(Y)=$ $(1-\chi) Y^{1-\mu}$ is a concave function of pre-tax labor income. We estimate the income tax function parameters by running the following OLS regression on the BPS data set:

$$
\ln (Y-\widetilde{T}(Y))=\ln (1-\chi)+(1-\mu) \ln (Y) .
$$

Tax liabilities $\widetilde{T}(Y)$ are defined as federal income taxes minus eligible amounts of EITC and Food Stamp benefits, all computed by BPS. The estimated tax parameters are $\mu=0.1327$ and $\chi=0.1575$.

\footnotetext{
${ }^{11}$ The extended BPS data set is generated by the same code provided by BPS, except that it expands the age range to include age 21-30 households. In the data, we only consider noncollateralized debt and abstract from mortgage debt, car loans, and other collateralized debt.
} 


\subsection{Payroll Tax and Retirement Benefit}

The flat payroll tax in the model $\tau_{s s}$ is set to $7.65 \%$, based on the actual Social Security and Medicare tax rates on pre-tax income of employees. In the U.S., social security benefits are piecewise linear functions of average monthly past earnings over the working life. Additional rules govern benefits for spouses. A full representation of the U.S. social security system is costly in terms of computation, since it adds a continuous state variable to the recursive formulation of the problem. Hence we model the progressivity of the U.S. social security benefit formula starkly, by assuming that benefits $b$ per household are independent of past contributions. We calibrate $b$ to the average social security benefits for married retired households aged 62 and older between 1999 and 2009 in the Current Population Survey (CPS),

given by $\$ 18484$ in 2000 dollars. Since the benefits from Medicare are difficult to measure directly, we assume that they are proportional to the social security benefits, based on the ratio of Medicare tax rate to Social Security tax rate. Therefore, the retirement benefit $b$ in the model is calibrated to $\$ 18484 \times 7.65 \% / 6.2 \%=\$ 22807$ in 2000 dollars. This implies a retirement benefit relative to average earnings of age 30-57 households of 27\%, somewhat lower than the typical replacement rate in life cycle models since average earnings of married, working households aged 30-57 are significantly higher, and replacement rates lower, than in the overall population.

\subsection{Fixed Utility Cost of Female Participation}

In the data, both male and female workers have significant labor market nonparticipation rates. However, since the BPS results are based on a sample of households with working male members, we do not include an extensive margin of male labor supply decisions in the model. To generate empirically plausible female labor supply decisions along the extensive margin in the model, the fixed utility cost of female labor market participation $f$ is chosen such that the average female nonparticipation rate of households aged 30 to 57 is $20 \%$, as in the BPS data set.

\subsection{Preference Parameters}

With our preference specification, the parameters $1 / \sigma, \eta_{1}$, and $\eta_{2}$ are the consumption, male and female labor supply Frisch elasticities with respect to their own 
prices, i.e., $\eta_{c, p}, \eta_{h_{1}, w_{1}}$ and $\eta_{h_{2}, w_{2}}{ }^{12}$ Therefore, we directly adopt the values BPS estimate under the assumption of separability: $\sigma=1 / 0.578, \eta_{1}=0.528$, and $\eta_{2}=0.850$. The value of parameter $\psi_{1}$ scaling the disutility of male labor is calibrated such that the average male labor income of age 30-57 households in the model equals 1 (normalization). The value of $\psi_{2}$ for female labor is calibrated to match the ratio of average female labor supply to average male labor supply conditional on working, which is 0.733 in the BPS data set.

Table 1: Calibrated Model Parameters

\begin{tabular}{clc}
\hline Parameter & Governing & Value \\
\hline A. Preferences & \\
$\delta$ & discount rate of utility & $4.69 \times 10^{-3}$ \\
$\psi_{1}$ & disutility of male labor supply & 2.538 \\
$\psi_{2}$ & disutility of female labor supply & 1.953 \\
$\sigma$ & inverse of consumption Frisch elasticity & $1 / 0.578$ \\
$\eta_{1}$ & male labor supply Frish elasticity & 0.528 \\
$\eta_{2}$ & female labor supply Frisch elasticity & 0.850 \\
$f$ & fixed utility cost of female participation & 0.0306 \\
B. Wage Process & \\
$e^{g_{2, t}-g_{1, t}}$ & female-male wage trend ratio & 0.485 \\
$\sigma_{v_{1}}^{2}$ & variance of male permanent shocks & 0.0303 \\
$\sigma_{v_{2}}^{2}$ & variance of female permanent shocks & 0.0382 \\
$\sigma_{v_{1}, v_{2}}$ & covariance of permanent shocks & 0.0027 \\
$\sigma_{u_{1}}^{2}$ & variance of male transitory shocks & 0.0275 \\
$\sigma_{u_{2}}^{2}$ & variance of female transitory shocks & 0.0125 \\
$\sigma_{u_{1}, u_{2}}$ & covariance of transitory shocks & 0.0058 \\
C. Redistribution System & \\
$\mu$ & income tax progressivity & 0.1327 \\
$\chi$ & income tax level & 0.1575 \\
$\tau_{s s}$ & payroll tax & 0.0765 \\
$b$ & retirement benefits & 0.3703 \\
D. Financial Market & risk-free interest rate & \\
$r$ & borrowing constraints & 0.126 \\
\hline A & \\
\hline
\end{tabular}

Notes: This table reports the values of parameters in the model with additively separable preferences.

\footnotetext{
${ }^{12}$ Following the original BPS paper, Frisch elasticities are denoted by $\eta$. The meaning of subscripts are $c$ for consumption, $h_{j}$ for earner $j$ 's labor supply, $p$ for the price of consumption and $w_{j}$ for earner $j$ 's wage. For example, $\eta_{c, p}$ is the Frisch elasticity of consumption with respect to its own price.
} 
Table 1 summarizes the calibration of the model, and Table 2 reports the empirical calibration targets as well as the (near-perfect) fit of the model along these dimensions.

Table 2: Empirical Targets Matched

\begin{tabular}{lcc}
\hline Empirical Targets & Data & Model \\
\hline average male labor income & 1 & 1.000 \\
average female labor income | work & 0.491 & 0.491 \\
female-male ratio of average labor supply | work & 0.733 & 0.733 \\
average female non-participation rate & 0.20 & 0.200 \\
average net worth & 4.188 & 4.189 \\
median debt-to-income ratio | debt (age 21-30) & 0.163 & 0.163 \\
\hline
\end{tabular}

Notes: This table reports the empirical moments matched by the model with additively separable preferences. Moments are for age 30-57 households unless specified otherwise.

\section{Quantitative Results}

We now report, in Section 4.2, how well households are insured against individual wage shocks of both earners in the model, how this extent of insurance compares to the empirically estimated BPS transmission coefficients, and then evaluate the relative importance of various insurance mechanisms (labor supply adjustments, savings, progressive income tax, etc.). Prior to do so, we briefly document, in the next section, the model-implied mean and variance profiles over the life cycle of consumption, asset and labor supply, and compare them to the data. ${ }^{13}$

\subsection{Life Cycle Profiles in the Benchmark Economy}

Figure 1 displays average consumption, asset, and labor supply profiles from age 30 to 57, both for the model (solid blue lines) as well as the PSID data used by BPS (dotted lines with shaded $95 \%$ confidence intervals). As is common in life cycle models, assets rise over the life cycle as households accumulate wealth to fund retirement consumption (and because $r>\delta$ ), but also for precautionary reasons, to

\footnotetext{
${ }^{13}$ To generate these profiles, optimal household policy functions are solved numerically using a policy function iteration algorithm combined with the endogenous grid method proposed by Carroll (2006). The policy functions are then used to simulate a panel of 50000 households from age 21 to age 80 , although we only use observations from age 30 to 57 when comparing model implications to the BPS estimates, consistent with the data set they use. Details about the numerical method are provided in Appendix G.
} 
hedge against stochastic wage fluctuations. Assets in the model peak at retirement (age 65 in the model) and are then drawn down to fund retirement consumption (we do not display the latter part of the life cycle in the figure because there are no corresponding BPS data to compare to). Note that by age 30 households on average have accumulated significant assets, in the model and in the data (see the upper right panel of Figure 1).
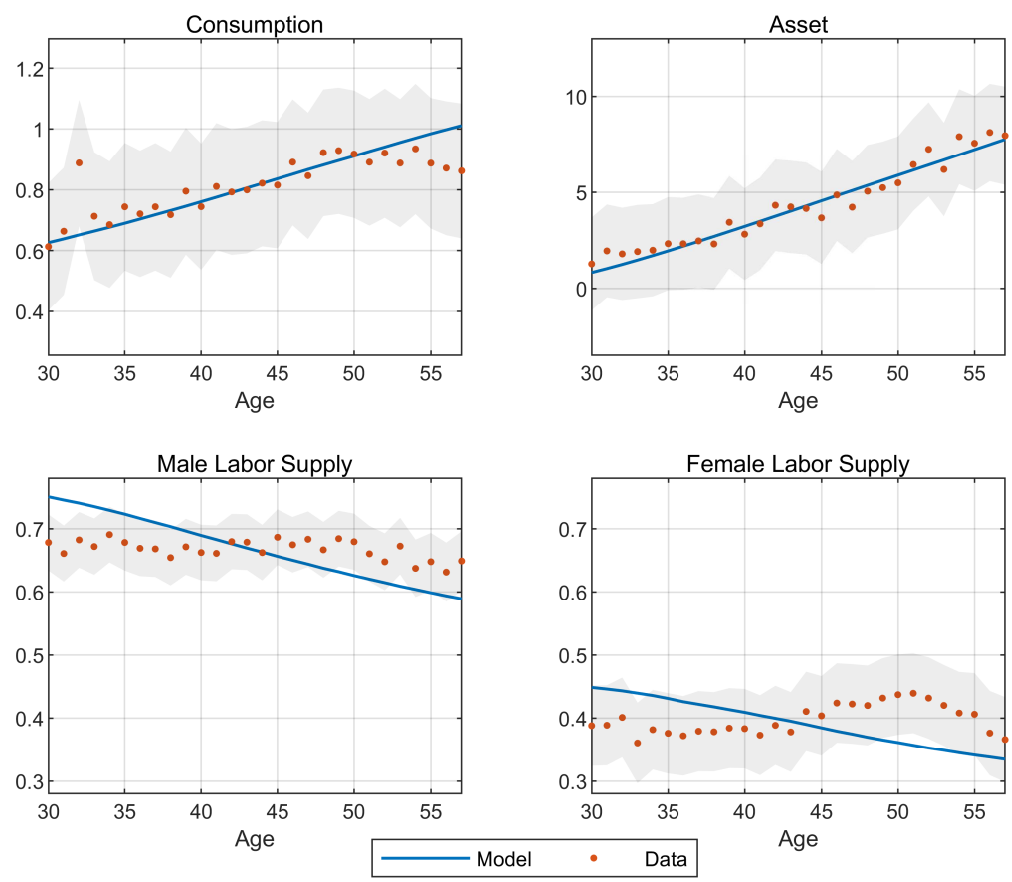

Figure 1: Life Cycles of Cross-sectional Means

Notes: This figure shows the life cycles of cross-sectional means in the benchmark model with additively separable preferences (solid lines) and in the data (dotted lines) together with the $95 \%$ confidence interval (grey bands). The data are from the BPS data set including age 30-57 households. The consumption life cycle from the data is scaled up to match the life-cycle average of consumption in the model.

Figure 2 plots the share of households that are borrowing constrained by age, and demonstrates that by age 30 essentially nobody in the economy is directly at the constraint, rendering the constraint fairly unimportant for the consumption and labor supply responses to wage shocks during the prime working years (30-57) of households. This is an important observation to keep in mind for the assessment of the potential bias of the BPS estimates (which rely on the assumption of interior 
allocations) in Section 4.2.4.

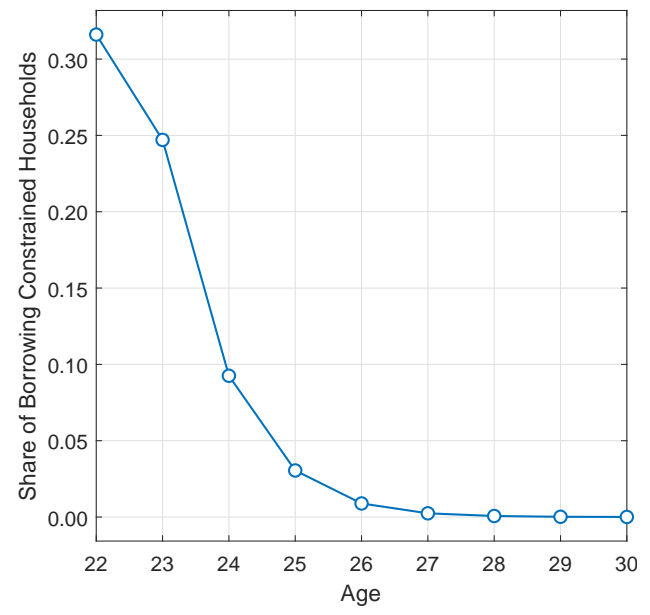

Figure 2: Share of Borrowing Constrained Households

Notes: This figure plots the share of young households on the borrowing constraints in the benchmark model with additively separable preferences.

Consumption in the model rises over the life cycle since wage and earnings risk, and the associated precautionary saving, as well as a fairly high degree of patience $(r-\delta \approx 1.5 \%$ ) lead to low consumption early in life, and subsequent positive consumption growth. Overall, the model captures well the growth of consumption and assets over the life cycle in the data. ${ }^{14}$

The bottom two panels of Figure 1 show average hours worked, separately for males and females, over the life cycle. For ease of comparison, we place average hours of males and females on the same scale. As will be clear from Figure 3, lower average female hours originate both from lower hours conditional on working, but also from a very significant non-participation rate (on average $20 \%$ of the population across all ages), both in the model as well as in the data (see the upper-right panel of the figure).

Figure 3 displays how consumption and hours dispersion, as measured by the variance of logs, evolve over the life cycle, and also shows female non-participation rates. ${ }^{15}$ In the model, consumption inequality is increasing over the life cycle as per-

\footnotetext{
${ }^{14}$ Since the consumption data do not include all types of consumption expenditures, in Figure 1, the life cycle consumption profile from the data is scaled up by a constant factor such that average consumption in the data is identical to that implied by the model.

${ }^{15}$ Since in the model households are ex-ante identical, the variances of all variables are zero at
} 

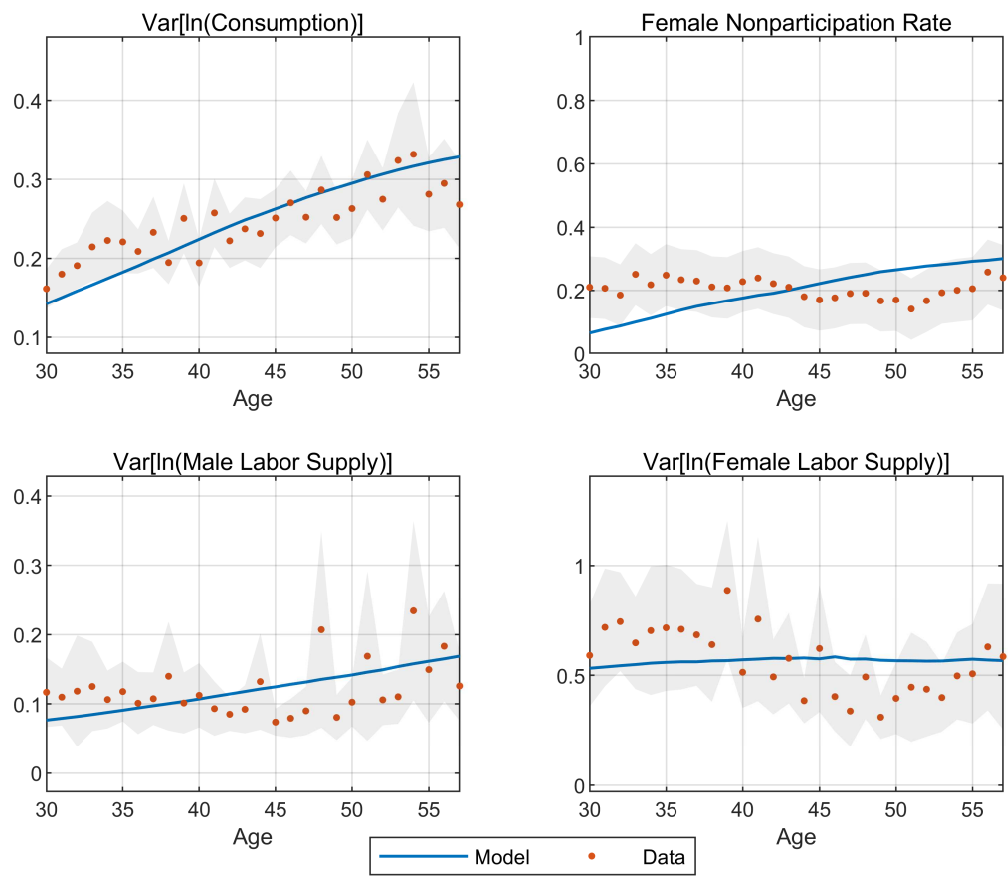

Figure 3: Life Cycles of Cross-sectional Variances and Female Non-participation

Notes: This figure shows the life cycles of cross-sectional variances and female non-participation rate in the benchmark model with additively separable preferences (solid lines) and in the data (dotted lines) together with the $95 \%$ confidence interval (grey bands). The data are from the BPS data set including age 30-57 households. The life cycles of variances in the model are shifted to match the life-cycle averages of variances in the data.

manent wage inequality rises strongly with age, on account of the very substantial exogenous permanent annual wage shocks (with variances of 0.030 and 0.038 , respectively) hitting both males and females. The model captures well not only the average consumption profile in the data, but also the evolution of consumption inequality over the life cycle. The model also matches the fairly flat life cycle variance profiles of the (model-endogenous) hours choices quite well (see the bottom panels of Figure 3)

Overall, even though our model does not give a perfect picture of averages and

the start of the life cycle at age 21. And since the model abstracts from other sources of household heterogeneity that might contribute to the variance of consumption and hours worked in the data, it is impossible for the model to match the level of the variances in the data. In Figure 3, the life-cycle variance profiles from the model are shifted by (variable-specific) constants such that, on average, the model variances match their counterparts in the data. The key question therefore is whether the model implies empirically plausible changes in the variances over the life cycle. 
inequality in the key endogenous economic choices over the life cycle, it especially captures very well both mean consumption and consumption inequality by age, crucial for a paper that focuses on the degree of, and mechanisms for, consumption insurance against wage shocks. In the next section we first describe how we measure this degree of consumption insurance, before documenting how well consumption is insulated from wage shocks in our model, and what roles the different mechanisms for providing that insurance play.

\subsection{The Transmission of Wage Shocks: Model vs Data}

\subsubsection{Measuring the Transmission of Wage Shocks}

The main applied purpose of our paper is to quantify how household labor supply, income, and consumption respond to wage shocks of its two members in our model, and how public insurance through the tax system shapes these responses. To measure these responses, Blundell, Pistaferri, and Preston (2008) and BPS introduce the concept of transmission coefficients and estimate them from the PSID data. Let lower case letters denote the logarithms of variables, so that $\Delta c_{t}$ and $\Delta y_{j, t}$ are the growth rates of household consumption and labor income of household member $j .{ }^{16}$ The responses of these household variables to permanent and transitory wage shocks are captured by the transmission coefficients $\kappa$ in the following equation:

$$
\left[\begin{array}{c}
\Delta c_{t} \\
\Delta y_{1, t} \\
\Delta y_{2, t}
\end{array}\right]=\left[\begin{array}{cccc}
\kappa_{c, u_{1}} & \kappa_{c, u_{2}} & \kappa_{c, v_{1}} & \kappa_{c, v_{2}} \\
\kappa_{y_{1}, u_{1}} & \kappa_{y_{1}, u_{2}} & \kappa_{y_{1}, v_{1}} & \kappa_{y_{1}, v_{2}} \\
\kappa_{y_{2}, u_{1}} & \kappa_{y_{2}, u_{2}} & \kappa_{y_{2}, v_{1}} & \kappa_{y_{2}, v_{2}}
\end{array}\right]\left[\begin{array}{c}
\Delta u_{1, t} \\
\Delta u_{2, t} \\
v_{1, t} \\
v_{2, t}
\end{array}\right] .
$$

The transmission coefficients therefore measure how consumption and labor income of household member $j \in\{1,2\}$ respond to transitory and permanent wage shocks. For example, $\kappa_{c, v_{j}}$ is the household consumption response to earner $j$ 's permanent wage shock. A value of $\kappa_{c, v_{j}}=0.4$ means that $40 \%$ of the shock passes through to household consumption, and hence $60 \%$ of it is insured. In the next section, we compute the transmission coefficients of shocks $\kappa$ from Equation (4.1) in the model and contrast them to the empirical estimates by BPS, thereby assessing

\footnotetext{
${ }^{16}$ Empirically, $c_{t}$ and $y_{j, t}$ are the residuals of $\log$ consumption and log labor income of earner $j$ at age $t$ after controlling for the effects of household observable characteristics.
} 
how much insurance against wage risk households obtain in the model, and whether the model captures well the empirically observed transmission of these shocks.

\subsubsection{Transmission of Shocks in the Model and in the Data}

In model simulations, realizations of transitory and permanent wage shocks are known separately, in addition to household consumption and labor income. Thus, the transmission coefficients can be obtained directly from OLS regressions of Equation (4.1). BPS must estimate these transmission coefficients from the data without separate knowledge of the different wage shocks; their method was developed precisely to tackle this problem. From now on, results from model-simulated data are labeled as "Model True", ${ }^{17}$ whereas results estimated from the PSID data by BPS are labeled as "Data BPS".

Table 3 reports the "Model True" transmission coefficients, together with the "Data BPS" results. Since BPS only use data of households aged 30 to 57, the "Model True" transmission coefficients are based on model-simulated data for this age group as well.

Table 3: Transmission Coefficients in the Data and the Model

\begin{tabular}{lcc}
\hline & Data BPS & Model True \\
\hline$\kappa_{c, u_{1}}$ & $-0.14(0.07)$ & 0.01 \\
$\kappa_{c, u_{2}}$ & $-0.04(0.07)$ & 0.01 \\
$\kappa_{c, v_{1}}$ & $0.32(0.05)$ & 0.35 \\
$\kappa_{c, v_{2}}$ & $0.19(0.03)$ & 0.18 \\
$\kappa_{y_{1}, u_{1}}$ & $1.58(0.16)$ & 1.44 \\
$\kappa_{y_{1}, u_{2}}$ & $0.11(0.06)$ & -0.05 \\
$\kappa_{y_{1}, v_{1}}$ & $0.92(0.08)$ & 1.16 \\
$\kappa_{y_{1}, v_{2}}$ & $-0.22(0.04)$ & -0.19 \\
$\kappa_{y_{2}, u_{1}}$ & $0.17(0.11)$ & -0.12 \\
$\kappa_{y_{2}, u_{2}}$ & $1.88(0.23)$ & 1.76 \\
$\kappa_{y_{2}, v_{1}}$ & $-0.75(0.14)$ & -0.51 \\
$\kappa_{y_{2}, v_{2}}$ & $1.42(0.08)$ & 1.46 \\
\hline
\end{tabular}

Notes: The numbers inside parentheses are standard errors from BPS. Only households aged 30-57 are included.

Comparing the consumption transmission coefficients in the model economy

\footnotetext{
${ }^{17}$ Due to the large sample size of the simulated data we use, statistic errors are essentially zero. Hence the results from simulated data can be seen as the true values implied by the model.
} 
with the BPS estimates, we observe that the model implies almost perfect consumption insurance against transitory wage shocks. Only $1 \%$ of male and female temporary wage shocks pass through to household consumption. This result is common in life cycle models with self-insurance through saving and additively separable preferences, and is in line with BPS' estimates of statistically insignificant or marginally significant but economically small consumption responses to temporary wage shocks of both household members. More importantly, our model predicts that only about $35 \%$ of male and $18 \%$ of female permanent wage shocks pass through to household consumption. The corresponding estimates from BPS are $32 \%$ for shocks to the male and $19 \%$ for shocks to the female wage. Thus the model-implied consumption insurance against permanent wage shocks is quantitatively very close to the empirical estimates. Taking BPS' point estimates, the model can explain about $96 \%$ and $101 \%$ of the consumption insurance against permanent wage shocks. ${ }^{18}$

The table also shows that the model not only fits well the consumption insurance patterns in the data, but also gives an accurate account of the empirical transmissions of wage shocks to labor income (and thus labor supply). The responses of male and female labor income to their own transitory wage shocks, $\kappa_{y_{j}, u_{j}}$, are larger than one, indicating that labor supply increases when wages are temporarily high. ${ }^{19}$ In the model, transitory wage shocks have only a small wealth effect, and thus the substitution effect dominates the labor supply response. The small wealth effect also explains the slightly negative transmission coefficient $\kappa_{y_{j}, u_{-j}}$ to labor income of one spouse from a wage shock of the other spouse. ${ }^{20}$

The labor income transmission coefficients of one's own permanent wage shock, $\kappa_{y_{j}, v_{j}}$, are smaller than their transitory counterparts since labor supply responds less to own permanent wage shocks, on account of the stronger wealth effects that permanent shocks induce. In contrast, when one spouse receives a permanent wage shock, labor supply of the other spouse responds more strongly, compared to a

\footnotetext{
${ }^{18}$ Recall that one key finding of Kaplan and Violante (2010) was that there is substantially too little consumption insurance against permanent income shocks in Bewley-type models.

${ }^{19}$ The labor supply response to wage shocks can be deduced by subtracting the percentage change of wages due to a specific shock from the associated transmission coefficient to labor income.

${ }^{20}$ Since male wages are on average larger than female wages, so is the wealth effect and induced transmission coefficient on female earnings.
} 
transitory shock, again on account of the larger wealth effect on labor supply. The value of $\kappa_{y_{1}, v_{2}}=-0.19$ indicates that male labor supply increases by $0.19 \%$ in response to a permanent $1 \%$ decline in the female wage, and $\kappa_{y_{2}, v_{1}}=-0.51$ implies a strong positive response of female hours of $0.51 \%$ to a $1 \%$ permanent reduction in the male wage. These results suggest that the labor supply adjustment of spouses, and especially that of females, is a crucial adjustment mechanism for a household dealing with reductions of male wages, especially permanent ones. Crucially, comparing the transmission coefficients in the model economy (column 2) with their empirical counterparts, "Data BPS" (column 1 of Table 3), the model overall reproduces the main patterns in the data well, with qualitative or significant quantitative deviations mainly observed only in the magnitude of the cross income response of one household member to temporary wage shocks of the other member (which are negative but small in the model, and positive but statistically insignificant in the data).

\subsubsection{Age Profiles of Consumption Insurance}

The transmission coefficients in Table 3 are sample averages for all households aged 30 to 57 . Figure 4 documents that there is very substantial age heterogeneity in the response of consumption to wage shocks by household age. Perhaps not surprisingly, consumption is very well insured against transitory wage shocks of both earners, with insurance close to $100 \%$ (transmission $\kappa_{c, u_{j}}$ close to zero) after age 25. At very young ages (21-25) borrowing constraints are binding for a subset of households, and thus household consumption responds more strongly even to transitory shocks, especially those to male wages, see the lower panel of Figure 4. The transmission $\kappa_{c, v_{j}}$ of permanent wage shocks to consumption displays much more significant variation over the life cycle, with the amount of consumption insurance against permanent shocks strongly rising over the life cycle, as the top panel of Figure 4 indicates. Better consumption insurance is the result of increased asset accumulation and declining human wealth with household age, so that permanent wage shocks become less important for consumption the older the household turns. In their data, BPS also find increasing consumption insurance with age against permanent male wage shocks, another dimension along which the model is consistent with the empirical BPS estimates. 

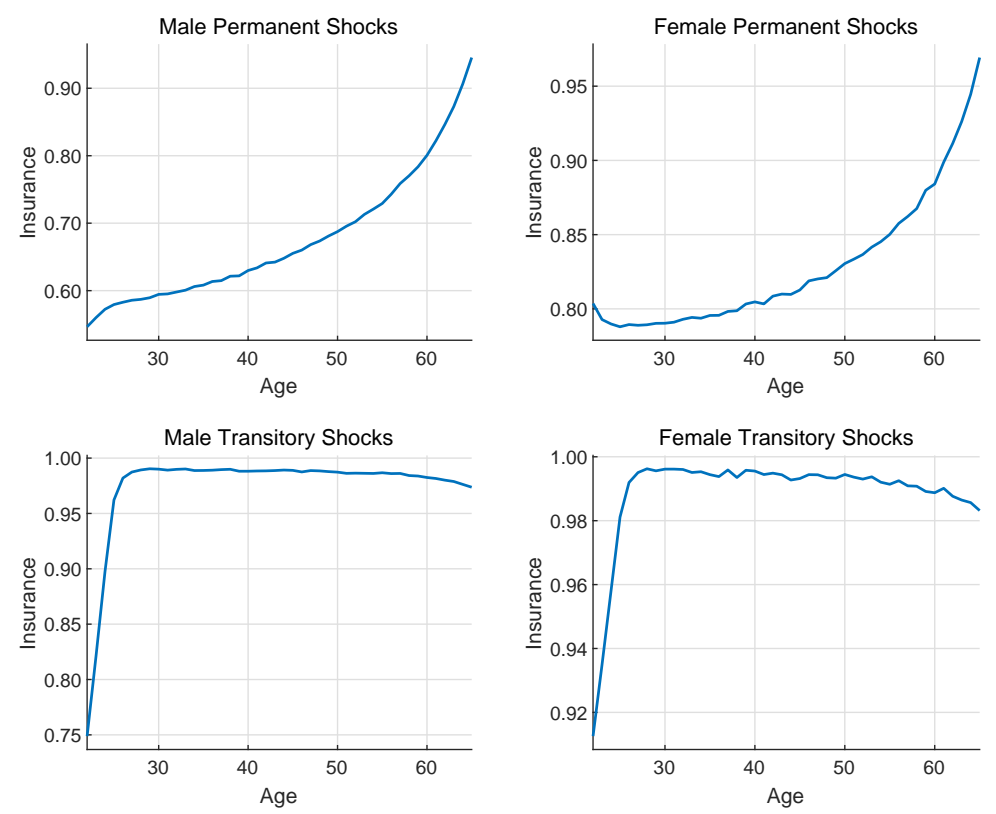

Figure 4: Age Profiles of Consumption Insurance

Notes: This figure plots consumption insurance over the life cycle against male (left) and female (right) permanent (top) and transitory (bottom) wage shocks in the benchmark model with additively separable preferences.

As Figure 10 in Appendix $\mathrm{C}$ shows, the transmission coefficient to male labor income from his own permanent wage shocks, $\kappa_{y_{1}, v_{1}}$, increases with age since the substitution effect on labor from higher wages is offset less by a declining wealth effect over the life cycle. That is, young households increase their male labor supply less than old households in response to a positive male permanent wage shock. ${ }^{21}$ Most notably, whereas in young ages female labor supply and thus female earnings respond quite strongly to an adverse permanent male wage shock $\left(\kappa_{y_{2}, v_{1}} \approx-75 \%\right)$, with age this adjustment mechanism becomes less potent $\left(\kappa_{y_{2}, v_{1}}\right.$ declines in absolute value) as older households primarily rely on assets to smooth consumption when confronted with a negative, permanent decline in male wages.

\subsubsection{Does the BPS Method Recover Well the Transmission of Wage Shocks in the Data?}

Thus far we have treated the BPS estimates of the transmission coefficients $\kappa$ as accurate representation of the true data. The purpose of this section is to evalu-

\footnotetext{
${ }^{21}$ Note that permanent wage shocks are only permanent until retirement, after which social security benefits set in. Consequently, permanent shocks later in life induce less of a wealth effect.
} 
ate whether this interpretation is justified, by assessing whether their methodology produces unbiased estimates of the true amount of insurance. We of course do not observe the true empirical data generating process, and therefore we conduct this analysis using simulated data from our model, for which we do in fact perfectly know the true transmission coefficients.

To briefly recap BPS' method, ${ }^{22}$ they show that if one log-linearizes the firstorder conditions and the intertemporal budget constraint of a two-earner household life cycle model very similar to the one described in Section 2, and assumes interior solutions (thus abstracting from binding borrowing constraints and extensive margin labor supply decisions), then the transmission coefficients $\kappa$ are given in closed form as functions $\kappa\left(\eta, \pi_{t}, s_{j, t}, \beta\right)$ of Frisch elasticities $\eta$, wealth shares $\left(\pi_{t}, s_{j, t}\right)$, and an "outside insurance" coefficient $\beta .^{23}$ The Frisch elasticities themselves are functions exclusively of the deep preference parameters in the household utility function if the latter is separable, but also depend on endogenous choices if it is not. The wealth share $\pi_{t}$ measures the share of financial wealth in total (human and financial) wealth, and the $s_{j, t}$ captures the share of household human wealth (present discounted value of future earnings) accruing to each earner $j \in\{1,2\}$.

BPS' method for estimating the transmission coefficients then encompasses four steps: (1) Estimate the variance-covariance matrices of the permanent and transitory wage shocks directly from wage data (with results that were documented in Section 3). (2) Measure the wealth shares $\pi_{t}$ and $s_{j, t}$ directly from the asset and labor income data. (3) Conditional on the results obtained from the first two steps, and using the empirical second-order moments of $\Delta c_{t}, \Delta y_{j, t}$, and $\Delta w_{j, t}$, employ a generalized method of moments (GMM) strategy to jointly estimate the Frisch elasticities $\eta$ and the "outside insurance" coefficient $\beta$ (unless the latter is restricted to zero). ${ }^{24}$

\footnotetext{
${ }^{22}$ Appendix D describes their method as implemented in this paper in detail.

${ }^{23} \mathrm{BPS}$ introduce this parameter to capture sources of household insurance that are not explicitly present in their (and our) model, such as insurance provided by networks of relatives and friends. Their baseline results are estimated under the restriction of $\beta=0$.

${ }^{24}$ For the baseline BPS estimates, no prior restrictions are imposed in estimation on the Frisch elasticities. The assumption of separability in the utility function translates into restrictions for the cross Frisch elasticities to be zero in the GMM estimation, and turns the Frisch elasticities into deep preference parameters in the utility function. In column 1 of Table 11 in Appendix C, we report the BPS estimates of these Frisch elasticities under the separability assumption, which we use as parameter values in our model, and thus labeled as "Model True"; they of course coincide
} 
Calculate the estimates of the transmission coefficients based on the closed form formulas $\kappa\left(\eta, \pi_{t}, s_{j, t}, \beta\right)$ stated explicitly in Appendix D. Since we control the data generating process, we know the true Frisch elasticities and implied transmission coefficients in the model, which we label as "Model True" in the tables below. The estimates based on model-simulated data to which the BPS methodology is then applied are denoted as "Model BPS". 25

To clarify the potential sources of the bias in the BPS estimates, recall that the BPS method imposes several assumptions to obtain a transparent and empirically operational methodology, and violations of these assumptions may result in biased estimates of the transmission coefficients. Their method is based on the loglinearization of the household optimality conditions, and thus it requires interiority of saving and labor supply decisions, and relies on a log-linear approximation of the true non-linear policy functions being accurate. These assumptions are systematically violated if borrowing constraints are frequently binding or if non-participation of one household member is ubiquitous, and the question is whether these violations are severe enough to spill over into significantly biased estimates of the wage shock transmission coefficients.

Table 4 reports the results for the transmission coefficients. The BPS method captures the degree of income and consumption insurance against transitory wage shocks almost perfectly. For permanent shocks, it captures the transmission of

with the values from the calibration Table 1. We also report the estimates of the Frisch elasticities if one applies the BPS methodology to model-simulated data. It confirms that, at least for modelgenerated data, the BPS method recovers the true elasticities well, especially if the outside insurance coefficient is permitted to be positive. The intertemporal elasticity of substitution in consumption and in male labor supply are very close to their true values. There is a slight downward bias in the female labor supply elasticity ( 0.81 v.s. the true 0.85 ), likely because the maintained assumption of interior female hours is violated in our model for a non-trivial share of observations.

${ }^{25}$ As an important aside, the description of the BPS method also allows us to clarify why the "Model True" transmission estimates might well deviate from the empirical estimates of BPS even though we employ their estimates of the Frisch elasticities (and thus preference parameters) and the stochastic wage process. Their estimates of the insurance coefficients depend on the joint distribution of the wealth shares $\pi_{t}$ and $s_{j, t}$ which they derive directly from the data, whereas they are the outcome of household saving and labor supply decisions in our model. Nothing guarantees that our model fits the data along these dimensions, and only if it does, will the transmission coefficients estimated by BPS and from our model line up closely. Our results above that the model fits the empirical BPS estimates well are therefore informative about whether our model is a good approximation of the true data generating process, at least for the aspects related to the consumption and labor income dynamics of prime-age households. 
Table 4: Estimation of Transmission Coefficients

\begin{tabular}{ccc}
\hline & Model True & Model BPS \\
\hline$\kappa_{c, u_{1}}$ & 0.01 & -0.02 \\
$\kappa_{c, u_{2}}$ & 0.01 & 0.02 \\
$\kappa_{c, v_{1}}$ & 0.35 & 0.42 \\
$\kappa_{c, v_{2}}$ & 0.18 & 0.22 \\
$\kappa_{y_{1}, u_{1}}$ & 1.44 & 1.47 \\
$\kappa_{y_{1}, u_{2}}$ & -0.05 & -0.03 \\
$\kappa_{y_{1}, v_{1}}$ & 1.16 & 1.10 \\
$\kappa_{y_{1}, v_{2}}$ & -0.19 & -0.20 \\
$\kappa_{y_{2}, u_{1}}$ & -0.12 & -0.10 \\
$\kappa_{y_{2}, u_{2}}$ & 1.76 & 1.76 \\
$\kappa_{y_{2}, v_{1}}$ & -0.51 & -0.62 \\
$\kappa_{y_{2}, v_{2}}$ & 1.46 & 1.53 \\
\hline
\end{tabular}

Notes: Based on households aged 3057.

female wage shocks to earnings and consumption well. It does, however, somewhat underestimates the consumption insurance against male wage shocks (overestimates the consumption transmission coefficient), and understates the transmission of male wage shocks into male and female earnings, with the latter bias likely due to the selection problem caused by the extensive margin of female labor supply. ${ }^{26}$ However, the main message of the table is that the magnitude of the bias in all cases is fairly small, and thus based on simulated model data we would conclude that the BPS estimates are likely good approximation to true insurance in the data, at least if the data are generated by a process close to our model. ${ }^{27}$

\footnotetext{
${ }^{26}$ The BPS "Baseline" method does not take into account consumption insurance through the social security system, which taxes labor income proportionally and pays benefits linked only imperfectly to past earnings. Ignoring social security underestimates consumption insurance. Column "SS" in Table 10 in Appendix C shows that including social security benefits when calculating the smoothing parameters $\left(\pi_{t}, s_{j, t}\right)$ cuts the bias in consumption insurance by more than half. Permitting outside insurance through the parameter $\beta$ (column "Outside") has the same effect.

${ }^{27}$ In the model we can base the estimation of transmission coefficients on an arbitrarily large sample, and therefore the model-based estimates we report have standard errors virtually equal to zero. Table 12 in Appendix C demonstrates that even if we estimate the transmission coefficients on a model sample size comparable to the BPS data, the resulting standard errors are very small (and an order of magnitude smaller than those in the data), suggesting that a) the actual data are much noisier than those generated from the model, and $b$ ) the results comparing model estimates to the data, and assessing the performance of the BPS method, are equally valid when using the smaller sample of simulated data.
} 


\subsubsection{Inspecting the Mechanisms: How Do Households Insure Against Wage Shocks?}

After having documented that households obtain substantial consumption insurance even against permanent wage shocks in the model, and showing that the extent of insurance accords well with the data (and demonstrating in the previous section that this is likely not an artefact of the BPS method), in this section we seek to better understand what mechanisms, quantitatively, are important for this finding. In our economy, households can smooth wage shocks through four basic mechanisms, two of which are exogenous to the household, and two involve active decisions. First, taking labor supply as given, the fact that wage shocks are imperfectly correlated among the two household members provides income and thus consumption insurance against individual wage fluctuations. Second, the social security system guarantees some income after retirement, which is independent of past wages and thus mitigates the impact of wage shocks on household lifetime income. Similarly, the progressive income tax code partially insulates after-tax income from pre-tax wage and thus earnings shocks. The two key margins along which households can adjust behavior in response to wage shocks are the labor supply of both members, both along the intensive and along the extensive margin, as well as the accumulation (and de-cumulation) of assets. Figure 8 in Appendix A shows how wage shocks of the male earner are mitigated through the various mechanisms before they end up in household consumption. Male wage shocks map male wages into male earnings, and the addition of female earnings (including female labor supply reactions) turns this into household pre-tax earnings. The progressive tax system maps pre-tax into after-tax earnings, and precautionary savings as well as the social security system shape the mapping between household after-tax earnings and consumption. Table 5 breaks down the extent of insurance achieved in each step of this mapping from male wages to consumption.

The table displays the transmission coefficient to consumption of permanent (upper panel) and transitory (lower panel) male wage shocks in a sequence of economies that differ in their availability of insurance mechanisms. Our discussion will focus mostly on the permanent wage shocks, since these are more important determinants of household welfare, are harder to insure, and it is with respect to 
Table 5: Consumption Insurance Decomposition (Male Shocks)

\begin{tabular}{|c|c|c|c|c|c|c|c|}
\hline \multirow[b]{3}{*}{ Economy } & \multicolumn{6}{|c|}{ Insurance Provided by } & \multirow{3}{*}{$\begin{array}{c}\text { Total } \\
\text { Insurance }\end{array}$} \\
\hline & \multirow{2}{*}{$\begin{array}{l}\text { Male } \\
\text { Earner }\end{array}$} & \multicolumn{3}{|c|}{ Female Earner } & \multirow{2}{*}{$\begin{array}{l}\text { Income } \\
\text { Tax }\end{array}$} & \multirow{2}{*}{$\begin{array}{c}\text { Savings+ } \\
\text { Social Security }\end{array}$} & \\
\hline & & Composition & Extensive & Intensive & & & \\
\hline \multicolumn{8}{|l|}{ A. Permanent Shock } \\
\hline 1-Earner, exogenous income & - & - & - & - & $13.3 \%$ & $33.7 \%$ & $47.0 \%$ \\
\hline+ male intensive margin & $-1.8 \%$ & - & - & - & $13.5 \%$ & $41.2 \%$ & $52.9 \%$ \\
\hline + female exogenous income & $-10.9 \%$ & $31.4 \%$ & - & - & $10.5 \%$ & $29.8 \%$ & $60.9 \%$ \\
\hline+ female extensive margin & $-11.5 \%$ & $27.4 \%$ & $5.1 \%$ & - & $10.5 \%$ & $30.1 \%$ & $61.6 \%$ \\
\hline+ female intensive margin & $-17.2 \%$ & $34.5 \%$ & $0.5 \%$ & $15.5 \%$ & $8.9 \%$ & $24.6 \%$ & $66.7 \%$ \\
\hline \multicolumn{8}{|l|}{ B. Transitory Shock } \\
\hline 1-Earner, exogenous income & - & - & - & - & $13.3 \%$ & $84.6 \%$ & $97.9 \%$ \\
\hline+ male intensive margin & $-40.0 \%$ & - & - & - & $18.6 \%$ & $119.4 \%$ & $98.0 \%$ \\
\hline + female exogenous income & $-42.8 \%$ & $38.6 \%$ & - & - & $13.8 \%$ & $88.4 \%$ & $98.0 \%$ \\
\hline+ female extensive margin & $-42.8 \%$ & $35.0 \%$ & $1.8 \%$ & - & $14.1 \%$ & $90.0 \%$ & $98.1 \%$ \\
\hline+ female intensive margin & $-43.2 \%$ & $42.1 \%$ & $0.3 \%$ & $4.2 \%$ & $12.8 \%$ & $81.4 \%$ & $97.7 \%$ \\
\hline
\end{tabular}

these shocks that Kaplan and Violante (2010) found the most significant deviations between theory (i.e. a standard Bewley model with exogenous earnings) and data (i.e. the estimates of Blundell, Pistaferri, and Preston (2008)). ${ }^{28}$ The table also breaks down, for each economy, how much of the consumption insurance is provided by labor supply and thus income adjustments of the male earner, the female earner, household income insurance through the progressive income tax system, as well as through asset accumulation and the progressive social security system (combined). ${ }^{29}$ For example, the first line shows that in an economy with exogenous labor supply where the female household member does not work and the male member works full-time, of a $1 \%$ permanent male wage shock $53 \%$ are transmitted to consumption, and $47 \%$ are insured. Since with exogenous labor supply and only one earner a male wage shock translates into an equally large household income shock, the only sources of insurance are the progressive income tax system (which insures

\footnotetext{
${ }^{28}$ We focus on the male wage shocks since they are quantitatively by far the most important one for household consumption, and because female wage shocks display the same qualitative results. All households aged 21-65 are included in the calculations of consumption insurance. In order to maximize comparability across economies we retain the same calibration across all models.

${ }^{29}$ Since the mapping between after-tax income and consumption is influenced both by private precautionary saving and the social security system, we cannot measure their insurance contribution in the model separately, short of solving a counterfactual model with one of the two elements absent.
} 
$13 \%$ of the pre-tax income decline) and consumption insurance through precautionary asset accumulation and redistributive public social security, which provide a further $34 \%$ consumption insurance. ${ }^{30}$ Fixing a row, the different columns decompose consumption insurance for a given economy, and moving across rows, the last column displays how much extra consumption insurance is achieved by activating an additional adjustment mechanism.

Comparing total consumption insurance (last column) across rows, we see that whereas in the one-earner model with exogenous labor supply, more than $50 \%$ of a permanent wage shock transmits to consumption, the presence of a second earner and endogenous labor supply adjustments of both spouses drive up that insurance to about $2 / 3$ of the shock (66.7\%). Thus consumption insurance increases by about 20 percentage points due to these mechanisms. The column also demonstrates that it is the presence and labor supply adjustment of the second earner, rather than the labor supply response of the primary earner, that is responsible for the better insurance. The latter improves insurance by 5.9 percentage points, whereas the female earner contributes 13.8 percentage points of extra insurance, due to the fact that a) holding labor supply constant, she provides an independent source of income (the composition effect, supplying 8 percentage points of extra insurance), and b) she increases labor supply along the intensive and extensive margin (generating 5.8 percentage points of extra insurance). The intensive margin is relatively more important than the extensive margin, since in the benchmark model $80 \%$ of female individuals already participate (by calibration of the fixed cost of participation), therefore limiting the quantitative scope for adjustment along this margin.

The point that labor earnings responses of the second earner are crucial for consumption insurance against permanent wage shocks of the male earner is reinforced by decomposing the sources of insurance in the benchmark model, in the last row of Panel A of Table 5. With all insurance mechanisms present, male labor sup-

\footnotetext{
${ }^{30}$ This extent of consumption insurance through asset accumulation and social security is slightly higher than that documented in Kaplan and Violante (2010) (34\% vs their 23\%). Kaplan and Violante (2010) measure consumption insurance against shocks to after-tax income, whereas we quantify insurance against shocks to pre-tax income. Since we do not recalibrate, the one-earner, exogenous income economy has a higher asset-to-income ratio than the one in Kaplan and Violante (2010) (and a higher one than our benchmark economy as well as the data), implying better consumption insurance against permanent income shocks.
} 
ply actually falls in response to a negative permanent male wage shock, and thus a $1 \%$ decline in male wages leads to a $1.17 \%$ decline in male earnings. The fact that household consumption only falls by $0.33 \%$ again stems mainly from the presence of female earnings and labor supply adjustments of the female worker (overall insuring approximately $50 \%$ of the male earnings decline), and to a significant but secondary part from savings adjustment (24.6\%) and public income insurance through the progressive income tax system (8.9\%). This last observation also suggests that the presence of a secondary earner and the active adjustment of labor supply in response to male shocks will alter very significantly the welfare cost of these shocks and the demand for public insurance against them. We will return to this point in the next section of the paper. Of course, for transitory wage shocks, the lower panel of Table 5 shows that savings responses are the primary vehicle for providing consumption insurance (with female earners being an important secondary contributor), and that these shocks are almost perfectly insured, as standard permanent income logic suggests.

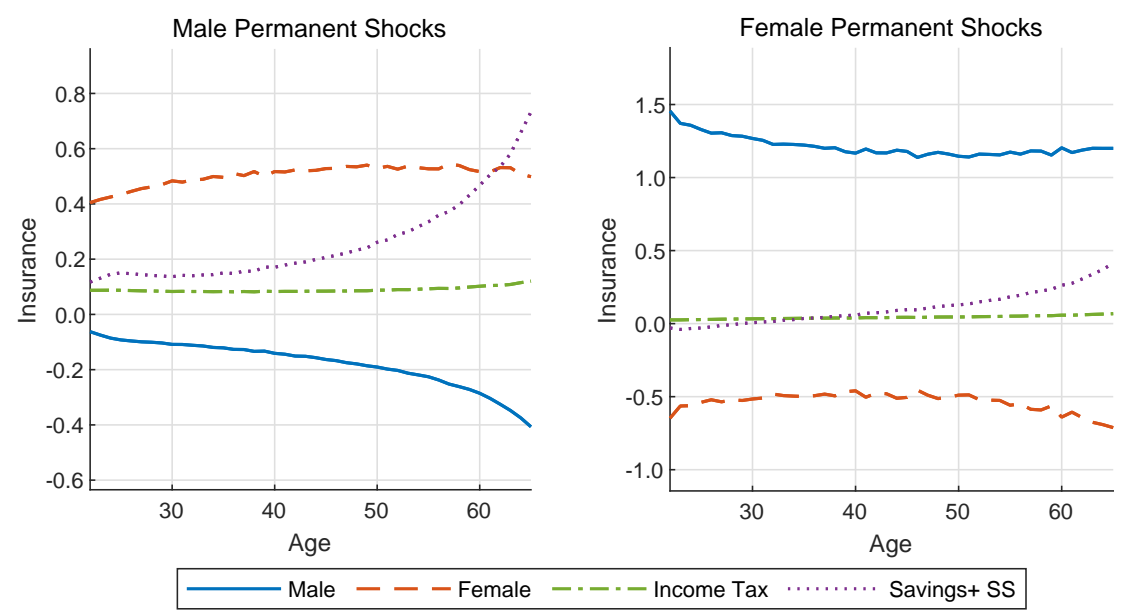

Figure 5: Age Profiles of Consumption Insurance Decomposition

Notes: This figure plots consumption insurance by source over the life cycle against male (left panel) and female (right panel) permanent wage shocks in the benchmark model with additively separable preferences. The sources are the male earner (solid line), the female earner (dash line), progressive income tax (dash-dot line), and savings plus social security (dotted line).

To briefly investigate whether the contributions of the insurance mechanisms we have highlighted in the previous table vary over the life cycle, in Figure 5 we plot the consumption insurance contributions for a permanent wage shock against 
household age. The left panel pertains to a permanent shock to male wages, whereas the right panel displays the results for a permanent female wage shock. We observe that, for all ages, the labor supply response of the person whose wage is hit by a permanent shock exacerbates the shock (i.e. the insurance contribution is negative, increasingly so as the household ages and the substitution effect increasingly dominates the wealth effect). Consistent with the main theme of Table 5, the labor supply of the other spouse is the most potent insurance mechanism, and is roughly constant over time, whereas the insurance provided by savings and social security keeps rising in importance over the life cycle, indicating that older households rely more on self-insurance through savings. This is also the main reason for the increasing age profile of total consumption insurance.

It is important to keep in mind that the degree of consumption insurance documented empirically by BPS pertains to a very specific (but large) subset of the overall population, the group of married two-earner households in prime working ages, and only to shocks to wages (as opposed to unemployment shocks, health shocks, shocks to family composition). In light of the importance of labor income of the secondary earner documented thus far, it is plausible to conjecture that households with other characteristics, especially single-earner households, could be subject to significantly less consumption insurance to the same type of wage shocks. Figure 6 verifies this conjecture, from the perspective of the model. It shows the total extent of consumption insurance (against permanent male wage shocks) for single-earner households over the life cycle, and contrasts it to that of the benchmark model. We observe that although both types of households display very similar consumption insurance in older ages, the consumption response to male wage shocks is significantly larger for single-earner households than for two-earner households in the model, especially if these single earners work in jobs where adjusting hours is difficult (the exogenous earnings model). Whereas even young (30-year old) households in the benchmark model can insure $60 \%$ of a male permanent wage shock, a single-earner 30 -year old with flexible hours attains only $40 \%$ of consumption insurance, and only $30 \%$ if working in professions with fixed hours. This point reinforces that there might be very significant heterogeneity in the population with respect to the consumption response to idiosyncratic wage shocks, and that the pres- 
ence and response of a second active earner in the household is a crucial dimension of heterogeneity to consider.

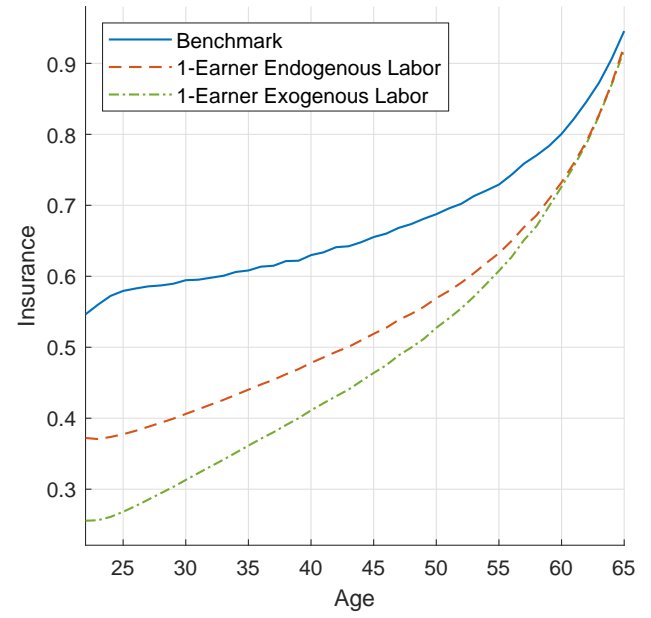

Figure 6: Age Profiles of Consumption Insurance in Three Models

Notes: This figure plots consumption insurance over the life cycle against male permanent wage shocks in three models with additively separable preferences.

\section{The Welfare Cost of Idiosyncratic Risk and Its Op- timal Insurance Revisited}

In this section we present our main economic application of the model, by revisiting the welfare cost of wage risk, as well as the optimal social insurance against this risk. In our model the household can self-insure against this risk not only by engaging in precautionary saving and changing labor supply of the primary earner (as is common in the literature), but also by adjusting labor supply along the extensive and intensive margin of the second earner of the family. We expect that this new margin reduces both the welfare cost of wage risk and the desirable degree of public insurance in the form of labor income tax progressivity. We now measure the extent to which this is true.

\subsection{Welfare Cost of Idiosyncratic Wage Risk}

We first quantify how much households are willing to pay to be completely insulated from idiosyncratic wage risk, in our benchmark model and in two comparison economies in which labor supply either cannot respond to the risk at all (column 3 
of Table 6), or the labor supply response is limited to the primary earner (column 2 of Table 6). In both these comparison economies female labor income is absent (and so is the composition effect, which, as we demonstrated above, is an important source of consumption insurance), and so is the opportunity of the household to adjust female labor supply in response to adverse male wage realizations.

Since all households are ex ante identical, we measure the welfare cost of wage risk as the percentage reduction in consumption (at each age, in each contingency) such that expected lifetime utility is identical in the absence and in the presence of wage risk. ${ }^{31}$ When changing the amount of idiosyncratic wage risk, we keep the life cycle profile of average wages constant across all economies. Since we study partial equilibrium models, there is no interaction across different age cohorts on labor or capital markets, and no impact of changing wage risk on aggregate factor prices.

Table 6 presents the results. It shows that, as well known from the literature, that even in the presence of self-insurance through saving the welfare losses from idiosyncratic income risk are large, in the order of $25 \%$ of lifetime consumption (see the first row of column 3 in the table). ${ }^{32}$ These losses stem primarily from the substantial permanent wage shocks that are difficult to insure against through precautionary saving. As the decomposition in the next rows shows ${ }^{33}$ essentially all

\footnotetext{
${ }^{31}$ Specifically, let $\left(\mathbf{c}^{0}, \mathbf{h}_{1}^{0}, \mathbf{h}_{2}^{0}\right)$ and $\left(\mathbf{c}^{1}, \mathbf{h}_{1}^{1}, \mathbf{h}_{2}^{2}\right)$ denote the allocation of consumption and labor supply before and after a change in wage risk, and $W\left(\mathbf{c}, \mathbf{h}_{1}, \mathbf{h}_{2}\right)$ be the welfare function that gives the lifetime utility under a particular consumption and labor supply allocation. The welfare cost of this change, in consumption-equivalent variation, $C E V$, is defined by
}

$$
W\left((1+C E V) \mathbf{c}^{0}, \mathbf{h}_{1}^{0}, \mathbf{h}_{2}^{0}\right)=W\left(\mathbf{c}^{1}, \mathbf{h}_{1}^{1}, \mathbf{h}_{2}^{1}\right) .
$$

\footnotetext{
${ }^{32}$ The absolute magnitude of these losses is at the high end of the numbers reported in the literature. For example, including initial risk at age 24, Karahan and Ozkan (2013) report a somewhat smaller welfare cost of $16.8 \%$ The main reason is that they estimate a smaller variance of permanent wage shocks than BPS (0.0113 vs 0.0303 in BPS). Another reason is that Karahan and Ozkan (2013) consider a shorter working life (24-60 vs $21-65$ in our model), and hence idiosyncratic wage risk is less important.

${ }^{33}$ Details about the decomposition of welfare changes are in Appendix B. As an example, the welfare change due to consumption change, $C E V_{C}$, is defined by
}

$$
W\left(\left(1+C E V_{C}\right) \mathbf{c}^{0}, \mathbf{h}_{1}^{0}, \mathbf{h}_{2}^{0}\right)=W\left(\mathbf{c}^{1}, \mathbf{h}_{1}^{0}, \mathbf{h}_{2}^{0}\right) .
$$

$C E V_{C}$ can be further decomposed into level and distribution effects, $C E V_{C L}$ and $C E V_{C D}$, defined 
the welfare losses are due to the fact that the higher income risk feeds into larger consumption risk. These conclusions are largely unchanged if labor supply of the primary earner is permitted to adjust in response to wage risk (compare columns 2 and 3 of the table), although household (i.e. male) average labor supply does increase in response to larger male wage risk, providing some consumption insurance against that risk. Overall, although the welfare loss from consumption risk falls by about 5 percentage points (compare the 4 th row in columns 2 and 3 ), this is achieved by on average larger, more dispersed, and therefore welfare-reducing labor supply, as rows 5-7 in column 2 display. Therefore, the overall welfare cost of wage risk is only modestly mitigated by the labor supply margin of the primary earner.

Table 6: Welfare Cost of Idiosyncratic Wage Risks

\begin{tabular}{lccc}
\hline & Benchmark & \multicolumn{2}{c}{ 1-Earner Household } \\
\cline { 3 - 4 } & Model & Endogenous Labor & Exogenous Labor \\
\hline A. Male Wage Risks & & & \\
Total Welfare Change & $-15.02 \%$ & $-23.16 \%$ & $-24.54 \%$ \\
Consumption & $-12.40 \%$ & $-20.60 \%$ & $-24.54 \%$ \\
$\quad$ Level & $1.22 \%$ & $-0.76 \%$ & $0.58 \%$ \\
$\quad$ Distribution & $-13.45 \%$ & $-19.99 \%$ & $-24.97 \%$ \\
Male Labor & $1.19 \%$ & $-3.23 \%$ & - \\
$\quad$ Level & $2.95 \%$ & $-1.30 \%$ & - \\
$\quad$ Distribution & $-1.71 \%$ & $-1.96 \%$ & - \\
Female Labor & $-4.13 \%$ & - & - \\
$\quad$ Level & $-4.23 \%$ & - & - \\
$\quad$ Distribution & $0.10 \%$ & - & - \\
B. Female Wage Risks & & & - \\
Total Welfare Change & $0.55 \%$ & - & - \\
C. All Wage Risks & & - & \\
Total Welfare Change & $-14.63 \% \%$ & & \\
\hline
\end{tabular}

Notes: This table reports the welfare changes due to the introduction of idiosyncratic wage risks (permanent and transitory) to different model economies. For the benchmark model, female wage risks are introduced first before male wage risks. Welfare changes are reported in consumption-equivalent variations (CEV), and details about the decomposition of welfare changes are in Appendix B.

by

$$
\begin{gathered}
W\left(\left(1+C E V_{C L}\right) \mathbf{c}^{0}, \mathbf{h}_{1}^{0}, \mathbf{h}_{2}^{0}\right)=W\left(\frac{\overline{\mathbf{c}}^{1}}{\overline{\mathbf{c}}^{0}} \mathbf{c}^{0}, \mathbf{h}_{1}^{0}, \mathbf{h}_{2}^{0}\right), \\
W\left(\left(1+C E V_{C D}\right)\left(1+C E V_{C L}\right) \mathbf{c}^{0}, \mathbf{h}_{1}^{0}, \mathbf{h}_{2}^{0}\right)=W\left(\mathbf{c}^{1}, \mathbf{h}_{1}^{0}, \mathbf{h}_{2}^{0}\right),
\end{gathered}
$$

where $\overline{\mathbf{c}}^{0}$ and $\overline{\mathbf{c}}^{1}$ are the average consumption before and after the change. 
The comparison with our benchmark model with endogenous labor supply response opportunities of the secondary earner (column 1) demonstrates that this is a very effective mechanism for dealing with wage risk of the primary earner, with the overall welfare cost from that risk being reduced by $39 \%$ (15.0\% instead of $24.5 \%$, see row 1, columns 1 and 3). Most of this reduction stems from better consumption insurance afforded by the labor supply response of the secondary earner (comparing rows 2 and 4 across the three columns of Table 6). Importantly, as the remaining rows of column 1 show, now male labor supply can fall when male wage realizations are low as the female member of the household can start to work, or work longer hours, to compensate the male income loss. ${ }^{34}$ The implied welfare losses from extended female hours are partially offset by the welfare gains of shorter male hours. Overall, however, uninsured consumption risk remains the largest cost of idiosyncratic wage risk of the primary earner, but with the secondary labor supply margin acting as a quantitatively very important mitigating factor.

This improved private insurance against wage risk can also plausibly be expected to reduce the demand for public income insurance. In the next subsection we now demonstrate this point by revisiting the optimal degree of labor income tax progressivity in the presence of joint household labor supply decisions.

\subsection{Optimal Public Insurance through Progressive Income Tax- ation}

To determine the optimal degree of tax progressivity we maximize expected lifetime utility of a newborn household with respect to the tax progressivity parameter $\mu$, and adjusting the tax level parameter $\chi$ such that the present discounted value (at the fixed interest rate $r$ ) of taxes paid by the cohort over its life cycle remains constant, and thus all potential policy reforms are revenue neutral. We conduct this thought experiment both for the benchmark economy with endogenous female labor supply, and for the one-earner economy with endogenous labor supply from the

\footnotetext{
${ }^{34} \mathrm{As}$ Panel $\mathrm{B}$ of the table shows, introducing female wage risk is actually welfare improving, since it increases the option value of female labor supply: at high female wage realizations the female worker participates whereas at low wage realizations it is not worth incurring the fixed cost of participation.
} 
previous section. ${ }^{35}$ Our objective is to quantify how the optimal degree of public insurance changes in response to the better private household insurance afforded by family labor supply.

We summarize our main results in Figure 7 and Table 7 . To interpret these results, recall that the benchmark tax system is given by progressivity parameter $\mu=0.13$ and level parameter $\chi=0.16$. The table displays the optimal tax system (for each economy), as well as changes in aggregate variables as well as in welfare, relative to the initial status quo tax system (including a decomposition of the welfare gains). The figure plots, against the degree of tax progressivity, the change in welfare (measured as \% consumption equivalent variation) and consumption insurance against male permanent wage shocks, relative to the benchmark system $(\mu=0.13)$.

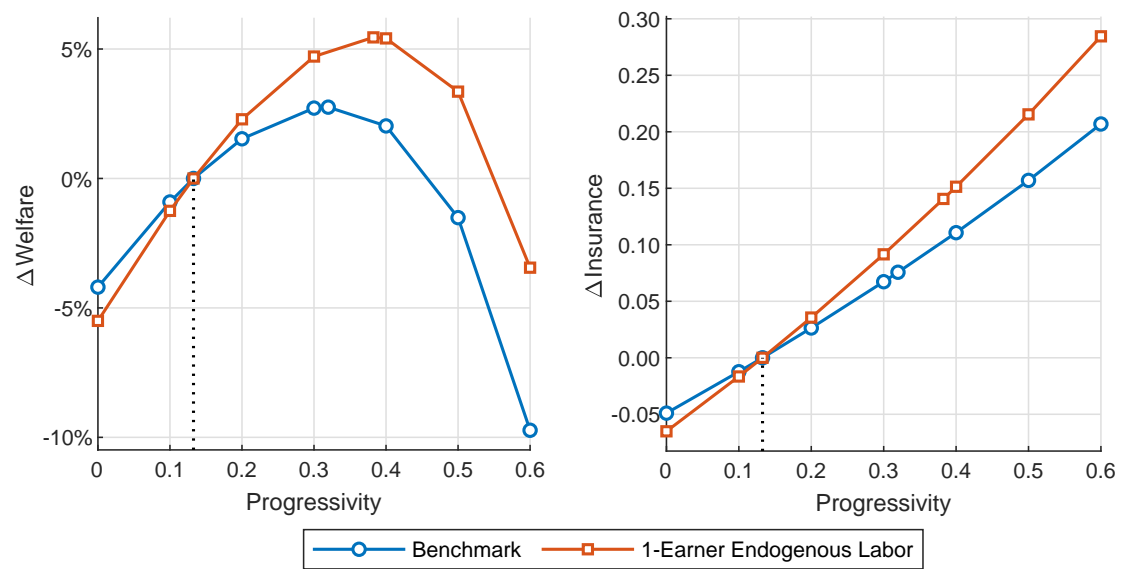

Figure 7: Welfare and Insurance Effects of Tax Progressivity

Notes: This figure shows how household welfare (left panel) and consumption insurance (right panel) change with income tax progressivity in two economies with additively separable preferences. Progressivity is measured by parameter $\mu$ in the tax function. Welfare changes are reported in consumption-equivalent variations. Consumption insurance is measured as one minus the transmission coefficient to consumption of male permanent wage shocks. The plots display the changes, relative to the benchmark tax system (i.e. $\mu=0.1327$ ).

The left panel of Figure 7 summarizes the two key results of this section. First, relative to the benchmark tax system a very significant increase in tax progressiv-

\footnotetext{
${ }^{35}$ If labor supply and thus earnings are exogenous as e.g. in Blundell, Pistaferri, and Preston (2008), then the optimal tax problem is trivial, since the government can provide full consumption insurance by taxing earnings at a confiscatory rate and redistributing the receipts in a lump-sum fashion.
} 
Table 7: Optimal Income Tax

\begin{tabular}{lcc}
\hline & $\begin{array}{c}\text { Benchmark } \\
\text { Model }\end{array}$ & $\begin{array}{c}\text { 1-Earner Household } \\
\text { Endogenous Labor }\end{array}$ \\
\hline A. Optimal Income Tax & & \\
Progressivity $(\mu)$ & 0.3197 & 0.3825 \\
Level $(\chi)$ & 0.1417 & 0.1807 \\
B. Changes in Aggregate Variables & \\
Consumption & $-11.13 \%$ & $-14.13 \%$ \\
Asset & $-17.88 \%$ & $-26.48 \%$ \\
Male Labor Supply & $-7.31 \%$ & $-10.76 \%$ \\
Female Labor Supply & $-12.78 \%$ & - \\
Male Labor Income & $-6.76 \%$ & $-10.03 \%$ \\
Female Labor Income & $-10.58 \%$ & - \\
Female Non-participation ${ }^{\mathrm{a}}$ & $2.87 \%$ & - \\
C. Welfare Gains & & \\
Total Welfare Gain & $2.75 \%$ & $5.45 \%$ \\
Consumption & $-3.73 \%$ & $-2.75 \%$ \\
$\quad$ Level & $-11.13 \%$ & $-14.13 \%$ \\
$\quad$ Distribution & $8.33 \%$ & $13.25 \%$ \\
$\quad$ Male Labor & $4.03 \%$ & $8.43 \%$ \\
$\quad$ Level & $3.77 \%$ & $7.73 \%$ \\
$\quad$ Distribution & $0.24 \%$ & $0.65 \%$ \\
Female Labor & $2.60 \%$ & - \\
$\quad$ Level & $2.75 \%$ & - \\
Distribution & $-0.14 \%$ & - \\
\hline
\end{tabular}

Notes: This table reports the optimal income tax policy and the effects of moving from the actual income tax to the optimal one. Welfare changes are reported in consumption-equivalent variations (CEV), and details about the decomposition of welfare changes are in Appendix B. ${ }^{\text {a }}$ The number reported is the actual change in female non-participation rate.

ity strongly improves welfare. More importantly, however, both the magnitude of the welfare gains as well as the optimal degree of tax progressivity fall very significantly in the presence of better private insurance against male wage risk due to family labor supply. Concretely, the optimal tax progressivity parameter falls from 0.38 to 0.32 , and the welfare gains from implementing the optimal (within the class of tax functions considered here) are cut in half, from $5.45 \%$ of lifetime consumption to $2.75 \%$ of lifetime consumption. The sources of the welfare gains of a more progressive tax system are, as Table 7 clarifies, better consumption insurance and a reduction of utility-reducing male (and if endogenous, female) labor supply, which 
have to be traded off against lower average consumption associated with larger tax progressivity.

In the previous section we showed that private consumption insurance improves in the presence of female labor supply. The right panel of Figure 7 provides the corollary: while expanding public insurance through tax progressivity improves overall consumption insurance, it does less so in the benchmark economy with flexible labor supply of the secondary earner. Consequently, abstracting from the joint decision of family labor supply has the potential of very significantly biasing the optimal degree of tax progressivity and the welfare benefits associated with it.

\section{Robustness}

In this section we briefly revisit two important assumptions made in the benchmark model that might affect the results in a quantitatively important way. First, we vary the tightness of borrowing constraints, and second, we relax the assumption of preferences that are additively separable between consumption and labor.

\subsection{Importance of the Tightness of Borrowing Constraints}

In the benchmark model we calibrated the tightness of borrowing constraints in such a way that the model matches the debt-to-income ratio of young (aged 21-30) households in the data. Table 8 displays results for the degree of consumption insurance against transitory and permanent male wage shocks (and its decomposition) in the benchmark economy, and in two economies in which borrowing is either ruled out altogether (Zero BC) and in which the constraints are set so large as to never be binding (Non-Binding BC). As in Table 5, households aged 21-65 are included in the calculation of consumption insurance in Table 8 .

As the table demonstrates, the degree of consumption insurance against permanent wage shocks, as well as its sources, are virtually unaffected by the tightness of the constraints. The impact on insurance against transitory shocks is more noticeable, and as expected: consumption insurance declines as the borrowing constraints tighten. The magnitude of this change is moderate, however, with $98.7 \%$ of the shock insured if borrowing constraints are not binding, and $97.4 \%$ if households cannot borrow at all. Interestingly, there is some substitution in the sources of insurance: as borrowing constraints tighten, the importance of savings for consumption 
Table 8: Borrowing Constraints and Consumption Insurance

\begin{tabular}{|c|c|c|c|c|c|c|c|}
\hline \multirow[b]{3}{*}{ Economy } & \multicolumn{6}{|c|}{ Insurance Provided by } & \multirow{3}{*}{$\begin{array}{c}\text { Total } \\
\text { Insurance }\end{array}$} \\
\hline & \multirow{2}{*}{$\begin{array}{l}\text { Male } \\
\text { Earner }\end{array}$} & \multicolumn{3}{|c|}{ Female Earner } & \multirow{2}{*}{$\begin{array}{c}\text { Income } \\
\operatorname{Tax}\end{array}$} & \multirow{2}{*}{$\begin{array}{c}\text { Savings+ } \\
\text { Social Security }\end{array}$} & \\
\hline & & Composition & Intensive & Extensive & & & \\
\hline \multicolumn{8}{|c|}{ A. Permanent Shock } \\
\hline Zero BC & $-17.1 \%$ & $34.5 \%$ & $15.5 \%$ & $0.4 \%$ & $8.9 \%$ & $24.5 \%$ & $66.7 \%$ \\
\hline Benchmark & $-17.2 \%$ & $34.5 \%$ & $15.5 \%$ & $0.5 \%$ & $8.9 \%$ & $24.6 \%$ & $66.7 \%$ \\
\hline Non-Binding BC & $-17.3 \%$ & $34.5 \%$ & $15.5 \%$ & $0.4 \%$ & $8.9 \%$ & $25.0 \%$ & $66.9 \%$ \\
\hline \multicolumn{8}{|l|}{ B. Transitory Shock } \\
\hline Zero BC & $-42.9 \%$ & $42.0 \%$ & $4.4 \%$ & $0.2 \%$ & $12.8 \%$ & $80.8 \%$ & $97.4 \%$ \\
\hline Benchmark & $-43.2 \%$ & $42.1 \%$ & $4.2 \%$ & $0.3 \%$ & $12.8 \%$ & $81.4 \%$ & $97.7 \%$ \\
\hline Non-Binding BC & $-44.0 \%$ & $42.3 \%$ & $3.8 \%$ & $0.4 \%$ & $12.9 \%$ & $83.3 \%$ & $98.7 \%$ \\
\hline
\end{tabular}

Notes: This table reports the decomposition results of consumption insurance against male permanent and transitory wage shocks in three model economies: a model with zero borrowing constraints (BC), the benchmark model, and a model with non-binding borrowing constraints (20 times the borrowing constraints in the benchmark model). Households aged 21-65 are included. Total Insurance $=$ $\sum_{m}$ Insurance $(m)$. Details about the decomposition method are in Appendix A

insurance declines, and female labor supply adjustments play a larger role in dealing with the shock. We conclude that our benchmark results are qualitatively and to a large degree quantitatively robust to the specification of borrowing constraints.

\subsection{Non-separable Preferences}

The key advantage of using the preference structure thus far is that the intertemporal and Frisch labor supply elasticities are exclusively determined by exogenous parameters which are therefore directly interpretable. However, it is restrictive in that it does not permit hours worked to affect the marginal utility of consumption (and vice versa). When BPS relax the assumption of separability in their estimation, they find important Frisch complementarity between consumption and leisure. In addition, introducing non-separable preferences into the model could, in principle, help it better capture aspects of the empirically estimated transmission coefficients the benchmark model had difficulty with, for example, the negative consumption response to positive transitory wage shocks $\left(\kappa_{c, u_{j}}<0\right)$. In this section we therefore modify the utility function to a non-separable (between consumption and labor of the two spouses) form:

$$
u\left(C, H_{1}, H_{2}\right)=\frac{\left\{\alpha C^{\gamma}+(1-\alpha)\left[\xi H_{1}^{\theta}+(1-\xi) H_{2}^{\theta}\right]^{-\frac{\gamma}{\theta}}\right\}^{\frac{1-\sigma}{\gamma}}-1}{1-\sigma} .
$$


Here $\gamma$ governs the substitution pattern between consumption and labor supply, and $\theta$ governs the substitution pattern between male and female labor supply. The main advantage of this utility function is that it is flexible enough to accommodate different substitution patterns between consumption and labor supply of both spouses. However, now the simple mapping between the preference parameters and the Frisch elasticities BPS estimate is lost, in that the Frisch elasticities are no longer deep parameters, but rather depend on the endogenous choices by households as well as the parameters $(\alpha, \xi, \gamma, \theta, \sigma)$.

The purpose of this section is to document how the degree of consumption insurance in the model is impacted by the non-separable utility specification, and to investigate the extent to which it helps the model match the empirically estimated transmission coefficients. Table 9 (transmission coefficients, equivalent of Table 3) summarize the most relevant results. The complete set of findings, including the calibration of the model, the model-implied life cycle profiles, estimates of modelimplied Frisch elasticities, decomposition of insurance into various mechanisms and an evaluation of the biases of the BPS method with the non-separable utility are available in Appendix E.

Table 9: Transmission Coefficients with Non-separable Preferences

\begin{tabular}{lccc}
\hline & Data & \multicolumn{2}{c}{ Model True } \\
\cline { 3 - 4 } & BPS & Separable & Non-separable \\
\hline$\kappa_{c, u_{1}}$ & $-0.14(0.07)$ & 0.01 & -0.15 \\
$\kappa_{c, u_{2}}$ & $-0.04(0.07)$ & 0.01 & -0.07 \\
$\kappa_{c, v_{1}}$ & $0.32(0.05)$ & 0.35 & 0.24 \\
$\kappa_{c, v_{2}}$ & $0.19(0.03)$ & 0.18 & 0.13 \\
$\kappa_{y_{1}, u_{1}}$ & $1.58(0.16)$ & 1.44 & 1.70 \\
$\kappa_{y_{1}, u_{2}}$ & $0.11(0.06)$ & -0.05 & 0.09 \\
$\kappa_{y_{1}, v_{1}}$ & $0.92(0.08)$ & 1.16 & 0.98 \\
$\kappa_{y_{1}, v_{2}}$ & $-0.22(0.04)$ & -0.19 & -0.27 \\
$\kappa_{y_{2}, u_{1}}$ & $0.17(0.11)$ & -0.12 & 0.18 \\
$\kappa_{y_{2}, u_{2}}$ & $1.88(0.23)$ & 1.76 & 1.62 \\
$\kappa_{y_{2}, v_{1}}$ & $-0.75(0.14)$ & -0.51 & -0.47 \\
$\kappa_{y_{2}, v_{2}}$ & $1.42(0.08)$ & 1.46 & 1.16 \\
\hline
\end{tabular}

Notes: The numbers inside parentheses are standard errors from BPS. Only households aged 30-57 are included.

Relative to the benchmark (second column of Table 9), in the model with non- 
separable preferences (third column) consumption and leisure are Frisch complements, and thus higher labor supply (lower leisure) reduces the marginal utility of consumption, and higher consumption increases the marginal disutility of labor supply. This change mainly impacts the labor supply and consumption response to transitory wage shocks. These shocks have only a small wealth effect, and thus their impact is largely determined by the substitution effect. But now a higher wage, inducing larger labor supply (lower leisure), drives down consumption due to the complementarity between consumption and leisure. As a result, household consumption responds mildly negatively to transitory wage shocks by both spouses $\left(\kappa_{c, u_{1}}<0, \kappa_{c, u_{2}}<0\right)$, as in the BPS estimates of the data. The same basic mechanism applies to permanent wage shocks (which have a much stronger wealth effect, though), which explains why now permanent wage shocks transmit to consumption even less strongly than in the separable case. Furthermore, since labor (leisure) of both spouses now are complements, positive transitory wage shocks of one spouse now induce a positive hours and thus earnings response of the other spouse $\left(\kappa_{y_{1}, u_{2}}>0, \kappa_{y_{2}, u_{1}}>0\right)$, again something found in the BPS estimates and hard to rationalize in the benchmark model.

Broadly speaking, the model with non-separable preferences matches the BPS estimates of the transmission coefficients of transitory shocks better, both quantitatively, but also qualitatively (in terms of their signs). Note, however, that most of these estimates are at most marginally statistically significant. On the other hand, it significantly overstates the degree of consumption insurance against permanent wage shocks, especially those of the primary earner (24\% transmission), relative to the empirical estimates, (32\% transmission) and relative to the benchmark model (35\% transmission). Since permanent wage shocks are the main sources of welfare losses from incomplete private insurance, and the main argument for the provision of public insurance, and the separable model fares better relative to the BPS estimates in this regard, we decided to conduct our analyses in Section 5 with the benchmark model, rather than the model with non-separable preferences. ${ }^{36}$ Over-

\footnotetext{
${ }^{36}$ Table 16 and 17 in Appendix E document the biases in the estimates of the Frisch elasticities and transmission coefficients, again based on simulated data. Overall, as in the separable case these biases are small, indicating that even with non-separable preferences the BPS method recovers the true Frisch elasticities and transmission coefficients well.
} 
all, however, our main conclusion from the previous section remains intact: the Bewley model with endogenous dual earner labor supply implies roughly as much insurance (if not more) against wage shocks, especially permanent wage shocks, as the empirical BPS estimates appear to exhibit. ${ }^{37}$

\section{Conclusions}

In this paper we have argued that a Bewley type model with two-earner households facing idiosyncratic wage shocks and making endogenous labor supply decisions replicates well quantitatively the extent of consumption insurance against permanent wage shocks estimated from U.S. micro household consumption data by Blundell, Pistaferri, and Saporta-Eksten (2016). These results suggest that life cycle models of the form employed in this work can be used in applications where the extent of consumption insurance, and the mechanisms through which it is achieved, are important. This includes the evaluation of social insurance and tax policies for which the adjustment of labor supply of both household members as well as savings responses can be expected to be important. We have demonstrated this for the case of progressive income taxation. Explicitly modeling spousal adjustments of earnings strongly reduces the welfare losses from wage risk of the primary earner as well as the desired extent of tax progressivity.

Given the importance of this mechanism, a next plausible step in this research agenda would be to investigate, in the context of this class of models, the optimal design of progressive taxation among both earners of the family, including the question whether to tax both partners jointly or separately, and whether to subject the primary and the secondary earner to systems with different degrees of progressivity.

\section{References}

Aiyagari, S. Rao. 1994. “Uninsured Idiosyncratic Risk and Aggregate Saving”. The Quarterly Journal of Economics 109 (3): 659-684.

\footnotetext{
${ }^{37}$ Table 19 in Appendix E (counterpart of Table 5) again decomposes consumption insurance into the various mechanisms. The main difference to the separable case is that now reducing male labor supply and increasing female labor supply at the same time is very costly (due to the complementarity of leisure), and thus male labor supply and consequently earnings do not fall much as in response to a negative male wage shock. The extent to which female labor income and savings are used to insure the lower male earnings is fairly similar across the two versions of the model, however.
} 
Attanasio, Orazio, Hamish Low, and Virginia Sánchez-Marcos. 2005. "Female Labor Supply as Insurance Against Idiosyncratic Risk". Journal of the European Economic Association 3 (2/3): 755-764.

Bénabou, Roland. 2002. "Tax and Education Policy in a Heterogeneous-Agent Economy: What Levels of Redistribution Maximize Growth and Efficiency?" Econometrica 70 (2): pp. 481-517.

Bewley, Truman. 1986. "Stationary Monetary Equilibrium with a Continuum of Independently Fluctuating Consumers". Contributions to Mathematical Economics in Honor of Gerard Debreu: 79-102.

Blundell, Richard, Luigi Pistaferri, and Ian Preston. 2008. “Consumption Inequality and Partial Insurance". American Economic Review 98 (5): 1887-1921.

Blundell, Richard, Luigi Pistaferri, and Itay Saporta-Eksten. 2016. "Consumption Inequality and Family Labor Supply”. American Economic Review 106 (2): $387-435$.

— . 2018. "Children, Time Allocation, and Consumption Insurance". Journal of Political Economy 126 (S1): S73-S115.

Carroll, Christopher D. 2006. “The Method of Endogenous Gridpoints for Solving Dynamic Stochastic Optimization Problems”. Economics Letters 91 (3): 312320.

Heathcote, Jonathan, Kjetil Storesletten, and Giovanni L. Violante. 2010. "The Macroeconomic Implications of Rising Wage Inequality in the United States". Journal of Political Economy 118 (4): 681-722.

— . 2014. "Consumption and Labor Supply with Partial Insurance: An Analytical Framework". American Economic Review 104 (7): 2075-2126.

Holter, Hans A., Dirk Krueger, and Serhiy Stepanchuk. 2019. "How Does Tax Progressivity and Household Heterogeneity Affect Laffer Curves?" Quantitative Economics, forthcoming.

Huggett, Mark. 1993. "The Risk-Free Rate in Heterogeneous-Agent IncompleteInsurance Economies". Journal of Economic Dynamics and Control 17 (5-6): 953-969. 
Imrohoroğlu, Ayşe. 1989. "Cost of Business Cycles with Indivisibilities and Liquidity Constraints". Journal of Political Economy 97 (6): 1364-1383.

Kaplan, Greg, and Giovanni L. Violante. 2010. "How Much Consumption Insurance beyond Self-Insurance?" American Economic Journal: Macroeconomics 2 (4): $53-87$.

Karahan, Fatih, and Serdar Ozkan. 2013. "On the Persistence of Income Shocks over the Life Cycle: Evidence, Theory, and Implications". Review of Economic Dynamics 16 (3): 452-476.

Ortigueira, Salvador, and Nawid Siassi. 2013. "How Important is Intra-Household Risk Sharing for Savings and Labor Supply?” Journal of Monetary Economics 60 (6): 650-666.

Park, Seonyoung, and Donggyun Shin. 2019. "Welfare Consequences of Rising Wage Risk in the United States: Self-Selection into Risky Jobs and Family Labor Supply Adjustments". Working Paper.

Rupert, Peter, and Giulio Zanella. 2015. "Revisiting Wage, Earnings, and Hours Profiles". Journal of Monetary Economics 72:114-130.

Santaeulàlia-Llopis, Raül, and Yu Zheng. 2018. "The Price of Growth: Consumption Insurance in China 1989-2009”. American Economic Journal: Macroeconomics 10 (4): 1-35. 


\section{On-line Appendix: For Review Only}

\section{A Consumption Insurance Decomposition}

In this section, we provide details on how consumption insurance decomposition is conducted based on model-simulated data within each row of Table 5 and in Figure 5. ${ }^{38}$ The idea of the decomposition is illustrated in Figure 8, which shows the transmission of a male wage shock to consumption in the model.

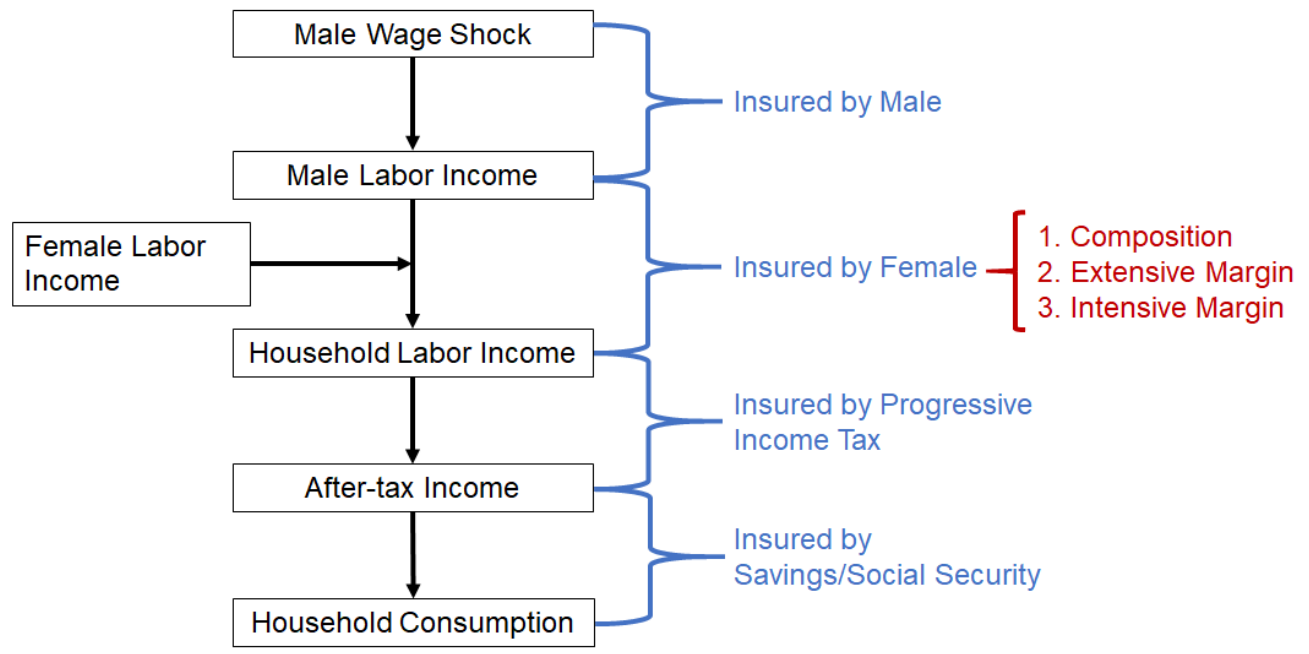

Figure 8: Transmission of Male Wage Shocks

For an age $t$ household, the percentage change of household income in response to a wage shock $x$ (i.e., $x=v_{j, t}$ or $x=\Delta u_{j, t}$ ) is approximately

$$
\begin{aligned}
\Delta y_{t} & =\frac{\Delta Y_{t}}{Y_{t-1}}=\frac{\Delta Y_{1, t}+\Delta Y_{2, t}}{Y_{t-1}} \\
& \approx \begin{cases}\frac{Y_{1, t-1}}{Y_{t-1}} \kappa_{y_{1}, x} x+\frac{Y_{2, t-1}}{Y_{t-1}} \kappa_{y_{2}, x} x, & \text { if } Y_{2, t-1}>0 ; \\
\frac{Y_{1, t-1}}{Y_{t-1}} \kappa_{y_{1}, x} x+\frac{\Delta Y_{2, t}}{Y_{t-1}}, & \text { if } Y_{2, t-1}=0,\end{cases}
\end{aligned}
$$

where $\kappa_{y_{1}, x}$ and $\kappa_{y_{2}, x}$ are transmission coefficients from shock $x$ to male and female labor income as defined in the main text, and by definition, they do not capture the

\footnotetext{
${ }^{38}$ For the decomposition in each row, the model is only solved once, and hence changes in household behaviors in response to changes in the set of available insurance channels are not taken into account. Such information is presented across different rows of Table 5 because the model is solved again whenever a new insurance channel is added.
} 
responses through extensive margin. Here we are assuming that the shock may only move the female earner into the labor market, which is innocuous because we can always switch the sign of the shock to make it true. Taking the expectation of $\Delta y_{t}$ over the distribution of households, we have the formula for the average response of household income with respect to shock $x$ :

$$
\begin{aligned}
& \mathbb{E}\left[\Delta y_{t}\right] \approx \mathbb{E}\left[\frac{Y_{1, t-1}}{Y_{t-1}}\right] \kappa_{y_{1}, x} x+\underbrace{\operatorname{Pr}\left(Y_{2, t-1}>0\right) \mathbb{E}\left[\frac{Y_{2, t-1}}{Y_{t-1}} \mid Y_{2, t-1}>0\right]}_{=\mathbb{E}\left[\frac{Y_{2, t-1}}{Y_{t-1}}\right]} \kappa_{y_{2}, x} x \\
& +\operatorname{Pr}\left(Y_{2, t-1}=0\right) \mathbb{E}\left[\frac{\Delta Y_{2, t}}{Y_{t-1}} \mid Y_{2, t-1}=0\right] .
\end{aligned}
$$

By rewriting Equation (A.1), we can decompose the average response of household income $\mathbb{E}\left[\Delta y_{t}\right]$ with respect to male wage shock $x$ into effects through different channels in the following way:

$$
\begin{aligned}
\mathbb{E}\left[\Delta y_{t}\right] & \approx\left\{1+\frac{\operatorname{Pr}\left(Y_{2, t-1}=0\right) \mathbb{E}\left[\frac{\Delta Y_{2, t}}{Y_{t-1}} \mid Y_{2, t-1}=0\right]}{\left[1+\frac{\mathbb{E}\left[\frac{Y_{2, t-1}}{Y_{t-1}}\right] \kappa_{y_{2}, x}}{\mathbb{E}\left[\frac{Y_{1, t-1}}{Y_{t-1}}\right] \kappa_{y_{1}, x}}\right] \mathbb{E}\left[\frac{Y_{1, t-1}}{Y_{t-1}}\right] \kappa_{y_{1}, x} x}\right\} \underbrace{\left[1+\frac{\mathbb{E}\left[\frac{Y_{2, t-1}}{Y_{t-1}}\right] \kappa_{y_{2}, x}}{\mathbb{E}\left[\frac{Y_{1, t-1}}{Y_{t-1}}\right] \kappa_{y_{1}, x}}\right]}_{K_{4}} \underbrace{}_{K_{3}} \underbrace{\times \underbrace{\mathbb{E}\left[\frac{Y_{1, t-1}}{Y_{t-1}}\right]}_{K_{2}} \underbrace{\kappa_{y_{1}, x}}_{K_{1}} x .} .
\end{aligned}
$$

where $K_{1}$ represents the effect of male intensive margin $\left(K_{1}=1\right.$ if male labor supply does not respond to the shock), $K_{2}$ represents the composition effect of female income ( $K_{2}=1$ if female labor income is zero), $K_{3}$ represents the effect of female intensive margin $\left(K_{3}=1\right.$ if female labor supply does not respond to the shock through intensive margin), and $K_{4}$ represents the effect of female extensive margin ( $K_{4}=1$ if females do not respond to the shock by entering the labor market).

We can calculate $K_{1}$ to $K_{3}$ easily because we can estimate $\kappa_{y_{j}, x}$ and $\mathbb{E}\left[\frac{Y_{j, t-1}}{Y_{t-1}}\right]$ from the model-simulated data. $\mathbb{E}\left[\frac{\Delta Y_{2, t}}{Y_{t-1}} \mid Y_{2, t-1}=0\right]$ is more difficult to calculate directly because $\Delta Y_{2, t}$ here is supposed to be the change of income in response to only the shock $x$. Therefore, to calculate $K_{4}$, we first regress $\Delta y_{t}$ on all shocks using model-simulated data to estimate the transmission coefficients from shock $x$ to household labor income directly, i.e., $\kappa_{y, x}$. By definition, we have

$$
\mathbb{E}\left[\Delta y_{t}\right]=\kappa_{y, x} x
$$


Combining Equation (A.1) and Equation (A.3), we have

$$
\operatorname{Pr}\left(Y_{2, t-1}=0\right) \mathbb{E}\left[\frac{Y_{2, t}}{Y_{t-1}} \mid Y_{2, t-1}=0\right] x^{-1}=k_{y, x}-\mathbb{E}\left[\frac{Y_{1, t-1}}{Y_{t-1}}\right] \kappa_{y_{1}, x}-\mathbb{E}\left[\frac{Y_{2, t-1}}{Y_{t-1}}\right] \kappa_{y_{2}, x} .
$$

And now we can calculate $K_{4}$ as well. ${ }^{39}$

By regressing $\Delta c_{t}$ on shocks using model-simulated data, we can also estimate the transmission coefficients from shock $x$ to consumption directly, i.e., $\kappa_{c, x}$, and hence

$$
\mathbb{E}\left[\Delta c_{t}\right]=\kappa_{c, x} x
$$

Given the functional form of the income tax function, we know

$$
\begin{aligned}
& \Delta y_{t}^{A T}=(1-\mu) \Delta y_{t} \\
\Rightarrow & \mathbb{E}\left[\Delta y_{t}^{A T}\right]=\underbrace{(1-\mu)}_{K_{5}} \kappa_{y, x} x,
\end{aligned}
$$

where $\Delta y_{t}^{A T}$ is the change of after-tax household income with respect to shock $x$, and $K_{5}$ represents the effect of progressive income tax ( $K_{5}=1$ if income tax is flat). Let $\mathbb{E}\left[\Delta c_{t}\right]=K_{6} \mathbb{E}\left[\Delta y_{t}^{A T}\right]$, we have

$$
\kappa_{c, x}=K_{6} K_{5} \kappa_{y, x}=\Pi_{m=1}^{6} K_{m} .
$$

And $K_{6}$ represents the effect of other insurance channels including household savings and social security in the model $\left(K_{6}=1\right.$ if consumption responds one for one to changes in after-tax income).

Based on Equation (A.5), we can decompose total consumption insurance based on the additional insurance generated through each insurance channel such that Total Insurance $=\sum_{m}$ Insurance $(m)$.

1. Insurance provided by male labor supply: $1-K_{1}$.

2. Insurance provided by the female earner: $\left(1-\Pi_{m=1}^{4} K_{m}\right)-\left(1-K_{1}\right)$.

(a) Composition effect: $\left(1-\Pi_{m=1}^{2}\right)-\left(1-K_{1}\right)$;

(b) Intensive margin: $\left(1-\Pi_{m=1}^{3}\right)-\left(1-\Pi_{m=1}^{2}\right)$;

(c) Extensive margin: $\left(1-\Pi_{m=}^{4}\right)-\left(1-\Pi_{m=1}^{3}\right)$.

\footnotetext{
${ }^{39}$ Since $\kappa_{y, x}=\Pi_{m=1}^{4} K_{m}$, we can simply calculate $K_{4}$ as $\kappa_{y, x} /\left(\Pi_{m=1}^{3} K_{m}\right)$. But we will still need Equation (A.4) for the decomposition of consumption insurance against female shocks.
} 
3. Insurance from progressive tax: $\left(1-\Pi_{m=1}^{5} K_{m}\right)-\left(1-\Pi_{m=1}^{4} K_{m}\right)$.

4. Insurance from other channels (savings and social security): $\left(1-\Pi_{m=1}^{6} K_{m}\right)-$ $\left(1-\Pi_{m=1}^{5} K_{m}\right)$.

For a female wage shock, we can decompose the effects of different channels in a similar way:

$$
\begin{aligned}
& \mathbb{E}\left[\Delta y_{t}\right] \approx\left[1+\frac{\mathbb{E}\left[\frac{Y_{1, t-1}}{Y_{t-1}}\right] \kappa_{y_{1}, x}}{\mathbb{E}\left[\frac{Y_{2, t-1}}{Y_{t-1}}\right]\left\{1+\frac{\left.\operatorname{Pr}\left(Y_{2, t-1}=0\right) \mathbb{E}\left[\frac{\left.\Delta Y_{2, t} \mid Y_{2, t-1}=0\right]}{Y_{t-1} \mid \frac{Y_{2, t-1}}{Y_{t-1}} \kappa_{y_{2}, x} x}\right\} \kappa_{y_{2}, x}\right]}{K_{4}}\right]}\right. \\
& \times \underbrace{\mathbb{E}\left[\frac{Y_{2, t-1}}{Y_{t-1}}\right]}_{K_{3}} \underbrace{\left\{1+\frac{\operatorname{Pr}\left(Y_{2, t-1}=0\right) \mathbb{E}\left[\frac{\Delta Y_{2, t}}{Y_{t-1}} \mid Y_{2, t-1}=0\right]}{\mathbb{E}\left[\frac{Y_{2, t-1}}{Y_{t-1}}\right] \kappa_{y_{2}, x} x}\right\} \underbrace{\kappa_{y_{2}, x}}_{K_{1}} x,}_{K_{K_{2}}}
\end{aligned}
$$

where $K_{1}$ represents the effect of female intensive margin, $K_{2}$ represents the effect of female extensive margin, $K_{3}$ represents the composition effect of male labor income, and $K_{4}$ represents the effect of male intensive margin. We can define the effect of progressive income tax $K_{5}$ and the effect of other channels $K_{6}$ in the same way as for male shocks.

\section{B Decomposition of Welfare Changes}

In this section, we explain how welfare changes in consumption-equivalent variations (CEV) and the decomposition of welfare changes into level and distribution effects of consumption and labor supply are calculated in the main text, for which we follow the method in Conesa, Kitao, and Krueger (2009).

Consider, for example, an income tax change in the model economy. Let $\mathbf{c}^{0}$ and $\left\{\mathbf{h}_{j}^{0}\right\}_{j=1}^{2}$ denote the state-contingent plan of household consumption and labor supply for a new-born household before the tax change, and let $W\left(\mathbf{c}^{0}, \mathbf{h}_{1}^{0}, \mathbf{h}_{2}^{0}\right)$ denote the expected lifetime utility of this new-born household under this state-contingent plan. After the tax change, the corresponding state-contingent plan is denoted by $\mathbf{c}^{1}$ and $\left\{\mathbf{h}_{j}^{1}\right\}_{j=1}^{2}$, and the lifetime utility is $W\left(\mathbf{c}^{1}, \mathbf{h}_{1}^{1}, \mathbf{h}_{2}^{1}\right)$.

The welfare effect of this tax change in consumption-equivalent variation, $C E V$, 
is defined by the following equation:

$$
W\left((1+C E V) \mathbf{c}^{0}, \mathbf{h}_{1}^{0}, \mathbf{h}_{2}^{0}\right)=W\left(\mathbf{c}^{1}, \mathbf{h}_{1}^{1}, \mathbf{h}_{2}^{1}\right) .
$$

Hence, $C E V$ is the percentage change of lifetime consumption that is required to generate a change of lifetime utility equal to that induced by the tax change. If $C E V$ is positive (negative), the tax change is welfare-improving (welfare-reducing).

We can decompose $C E V$ into components stemming from the change in consumption and the change in labor supply. The welfare change due to consumption change, $C E V_{C}$, is defined by the following equation:

$$
W\left(\left(1+C E V_{C}\right) \mathbf{c}^{0}, \mathbf{h}_{1}^{0}, \mathbf{h}_{2}^{0}\right)=W\left(\mathbf{c}^{1}, \mathbf{h}_{1}^{0}, \mathbf{h}_{2}^{0}\right) .
$$

And the welfare change due to changes in male and female labor supply, $C E V_{H_{1}}$ and $C E V_{H_{2}}$, are defined by:

$$
\begin{gathered}
W\left(\left(1+C E V_{H_{1}}\right)\left(1+C E V_{C}\right) \mathbf{c}^{0}, \mathbf{h}_{1}^{0}, \mathbf{h}_{2}^{0}\right)=W\left(\mathbf{c}^{1}, \mathbf{h}_{1}^{1}, \mathbf{h}_{2}^{0}\right), \\
W\left(\left(1+C E V_{H_{2}}\right)\left(1+C E V_{H_{1}}\right)\left(1+C E V_{C}\right) \mathbf{c}^{0}, \mathbf{h}_{1}^{0}, \mathbf{h}_{2}^{0}\right)=W\left(\mathbf{c}^{1}, \mathbf{h}_{1}^{1}, \mathbf{h}_{2}^{1}\right) .
\end{gathered}
$$

Therefore,

$$
(1+C E V)=\left(1+C E V_{C}\right)\left(1+C E V_{H_{1}}\right)\left(1+C E V_{H_{2}}\right) .
$$

Furthermore, the consumption impact on welfare can itself be divided into a part that captures the change in average consumption, and a part that reflects the change in the distribution of consumption across the life cycle and different states. Let $\overline{\mathbf{c}}^{0}$ and $\overline{\mathbf{c}}^{1}$ denote the average household consumption before and after the tax change, then the welfare change due to the change in consumption level, $C E V_{C L}$, is define by

$$
W\left(\left(1+C E V_{C L}\right) \mathbf{c}^{0}, \mathbf{h}_{1}^{0}, \mathbf{h}_{2}^{0}\right)=W\left(\frac{\overline{\mathbf{c}}^{1}}{\overline{\mathbf{c}}^{0}} \mathbf{c}^{0}, \mathbf{h}_{1}^{0}, \mathbf{h}_{2}^{0}\right),
$$

i.e., $C E V_{C L}=\overline{\mathbf{c}}^{1} / \overline{\mathbf{c}}^{0}-1$, which is the percentage change of average household consumption due to the tax change. The welfare change due to the change in the distribution of consumption, $C E V_{C D}$, is defined by

$$
W\left(\left(1+C E V_{C D}\right)\left(1+C E V_{C L}\right) \mathbf{c}^{0}, \mathbf{h}_{1}^{0}, \mathbf{h}_{2}^{0}\right)=W\left(\mathbf{c}^{1}, \mathbf{h}_{1}^{0}, \mathbf{h}_{2}^{0}\right) .
$$

And hence we have,

$$
\left(1+C E V_{C}\right)=\left(1+C E V_{C D}\right)\left(1+C E V_{C L}\right) .
$$

Similarly, for male and female labor supply changes, we can define $C E V_{H_{1} L}$, 
$C E V_{H_{1} D}, C E V_{H_{2} L}$, and $C E V_{H_{2} D}$ by

$$
\begin{gathered}
W\left(\left(1+C E V_{H_{1} L}\right)\left(1+C E V_{C}\right) \mathbf{c}^{0}, \mathbf{h}_{1}^{0}, \mathbf{h}_{2}^{0}\right)=W\left(\mathbf{c}^{1}, \frac{\overline{\mathbf{h}}_{1}^{1}}{\overline{\mathbf{h}}_{\mathbf{1}}^{0}} \mathbf{h}_{1}^{0}, \mathbf{h}_{2}^{0}\right), \\
W\left(\left(1+C E V_{H_{1} D}\right)\left(1+C E V_{H_{1} L}\right)\left(1+C E V_{C}\right) \mathbf{c}^{0}, \mathbf{h}_{1}^{0}, \mathbf{h}_{2}^{0}\right)=W\left(\mathbf{c}^{1}, \mathbf{h}_{1}^{1}, \mathbf{h}_{2}^{0}\right), \\
W\left(\left(1+C E V_{H_{2} L}\right)\left(1+C E V_{H_{1}}\right)\left(1+C E V_{C}\right) \mathbf{c}^{0}, \mathbf{h}_{1}^{0}, \mathbf{h}_{2}^{0}\right)=W\left(\mathbf{c}^{1}, \mathbf{h}_{1}^{1}, \frac{\overline{\mathbf{h}}_{\mathbf{2}}^{1}}{\overline{\mathbf{h}}_{\mathbf{2}}^{0}} \mathbf{h}_{2}^{0}\right),
\end{gathered}
$$

$W\left(\left(1+C E V_{H_{2} D}\right)\left(1+C E V_{H_{2} L}\right)\left(1+C E V_{H_{1}}\right)\left(1+C E V_{C}\right) \mathbf{c}^{0}, \mathbf{h}_{1}^{0}, \mathbf{h}_{2}^{0}\right)=W\left(\mathbf{c}^{1}, \mathbf{h}_{1}^{1}, \mathbf{h}_{2}^{1}\right)$, where $\overline{\mathbf{h}}_{1}^{0}, \overline{\mathbf{h}}_{1}^{1}, \overline{\mathbf{h}}_{2}^{0}$, and $\overline{\mathbf{h}}_{2}^{1}$ are average male and female labor supply before and after the tax change, and we have

$$
\begin{aligned}
& \left(1+C E V_{H_{1}}\right)=\left(1+C E V_{H_{1} D}\right)\left(1+C E V_{H_{1} L}\right), \\
& \left(1+C E V_{H_{2}}\right)=\left(1+C E V_{H_{2} D}\right)\left(1+C E V_{H_{2} L}\right) .
\end{aligned}
$$

\section{Supplementary Results for the Benchmark Model}

\section{C.1 Wage Profiles}

The life-cycle male wage trend is interpolated and extrapolated from Rupert and Zanella (2015) and plotted in Figure 9. The scale of it is normalized such that the average male trend wage is 1 . The female wage trend is rescaled from the male wage trend to match the ratio of the average earnings between working males and females in the BPS data set.

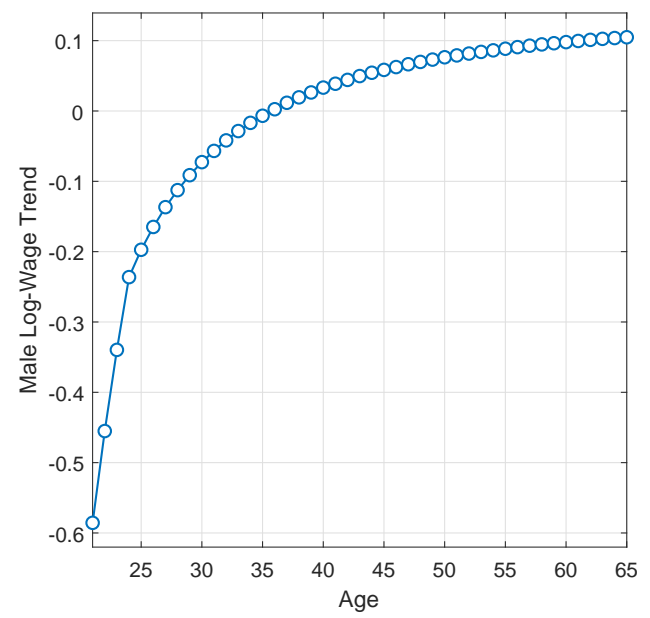

Figure 9: Male Log-Wage Trend

Notes: This figure shows the male log-wage trend used in the model. The female log-wage trend has the same shape but a different level that is calibrated to match the data. 


\section{C.2 Age Profiles of Transmission Coefficients}
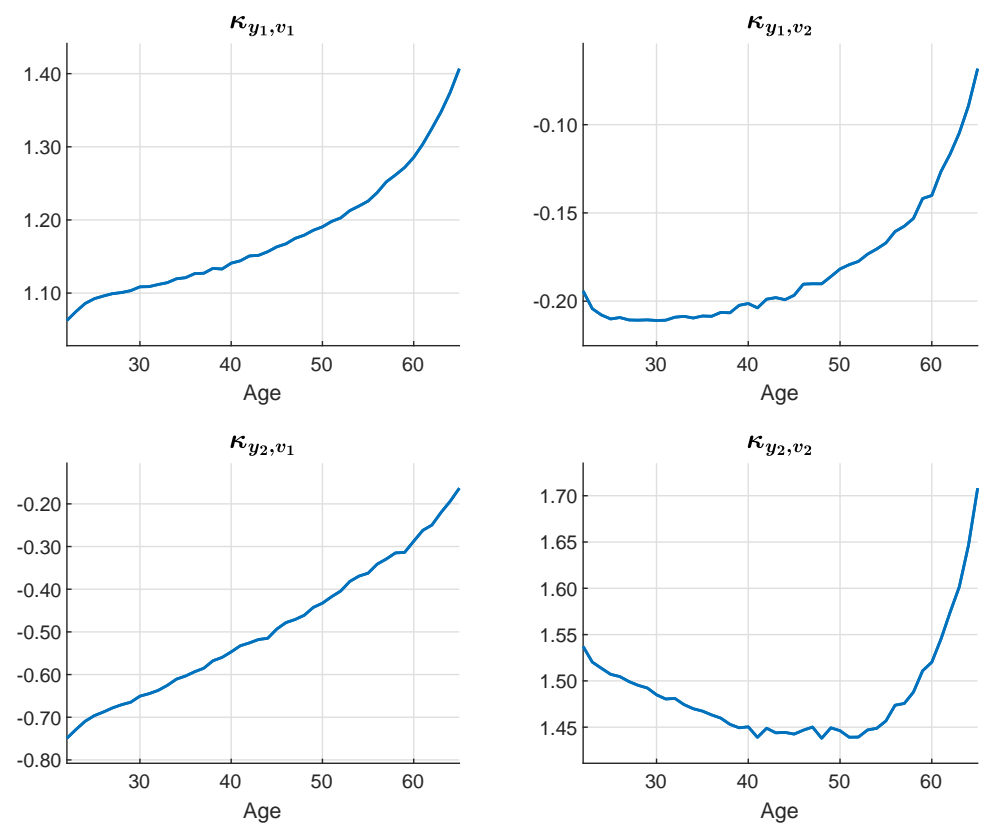

Figure 10: Age Profiles of Transmission Coefficients to Labor Income

Notes: This figure plots transmission coefficients to labor income from permanent wage shocks over the life cycle in the benchmark model with additively separable preferences.

\section{C.3 Performance of the BPS Method}


Table 10: Estimation of Transmission Coefficients (Extended)

\begin{tabular}{ccccc}
\hline & Model & \multicolumn{3}{c}{ Model BPS } \\
\cline { 2 - 5 } & True & Baseline $^{\mathrm{a}}$ & $\mathrm{SS}^{\mathrm{b}}$ & Outside $^{\mathrm{c}}$ \\
\hline$\kappa_{c, u_{1}}$ & 0.01 & -0.02 & -0.01 & 0.00 \\
$\kappa_{c, u_{2}}$ & 0.01 & 0.02 & 0.02 & 0.02 \\
$\kappa_{c, v_{1}}$ & 0.35 & 0.42 & 0.38 & 0.38 \\
$\kappa_{c, v_{2}}$ & 0.18 & 0.22 & 0.20 & 0.20 \\
$\kappa_{y_{1}, u_{1}}$ & 1.44 & 1.47 & 1.46 & 1.46 \\
$\kappa_{y_{1}, u_{2}}$ & -0.05 & -0.03 & -0.04 & -0.04 \\
$\kappa_{y_{1}, v_{1}}$ & 1.16 & 1.10 & 1.13 & 1.14 \\
$\kappa_{y_{1}, v_{2}}$ & -0.19 & -0.20 & -0.19 & -0.19 \\
$\kappa_{y_{2}, u_{1}}$ & -0.12 & -0.10 & -0.11 & -0.11 \\
$\kappa_{y_{2}, u_{2}}$ & 1.76 & 1.76 & 1.76 & 1.76 \\
$\kappa_{y_{2}, v_{1}}$ & -0.51 & -0.62 & -0.58 & -0.58 \\
$\kappa_{y_{2}, v_{2}}$ & 1.46 & 1.53 & 1.54 & 1.54 \\
\hline
\end{tabular}

Notes: Only households aged 30-57 are included. ${ }^{\text {a }}$ BPS baseline method.

${ }^{\mathrm{b}}$ Modified BPS method accounting for the social security system explicitly. $\quad{ }^{\mathrm{c}}$ BPS method allowing unspecified outside insurance. The outside insurance coefficient estimated here is $\beta=0.1460$.

Table 11: Estimation of Frisch Elasticities

\begin{tabular}{lcccc}
\hline & Model & \multicolumn{3}{c}{ Model BPS } \\
\cline { 3 - 5 } & True & Baseline $^{\mathrm{a}}$ & SS $^{\mathrm{b}}$ & Outside $^{\mathrm{c}}$ \\
\hline$\eta_{c, p}$ & 0.578 & 0.617 & 0.595 & 0.593 \\
$\eta_{c, w_{1}}$ & 0 & -0.014 & -0.002 & -0.002 \\
$\eta_{c, w_{2}}$ & 0 & 0.021 & 0.022 & 0.022 \\
$\eta_{h_{1}, p}$ & 0 & 0.012 & 0.002 & 0.002 \\
$\eta_{h_{1}, w_{1}}$ & 0.528 & 0.538 & 0.526 & 0.525 \\
$\eta_{h_{1}, w_{2}}$ & 0 & 0.003 & -0.005 & -0.005 \\
$\eta_{h_{2}, p}$ & 0 & -0.036 & -0.037 & -0.037 \\
$\eta_{h_{2}, w_{1}}$ & 0 & 0.005 & -0.010 & -0.010 \\
$\eta_{h_{2}, w_{2}}$ & 0.850 & 0.818 & 0.810 & 0.810 \\
\hline
\end{tabular}

Notes: Only households aged 30-57 are included.

${ }^{\text {a }}$ BPS baseline method.

${ }^{\mathrm{b}}$ Modified BPS method accounting for the social security system explicitly. $\quad{ }^{c}$ BPS method allowing unspecified outside insurance. The outside insurance coefficient estimated here is $\beta=0.1460$. 
Table 12: BPS Method in Small Samples

\begin{tabular}{cccccccc}
\hline & Data & & \multicolumn{2}{c}{ Model } & & \multicolumn{2}{c}{ Model (Small Sample) } \\
\cline { 2 - 3 } \cline { 7 - 8 } \cline { 6 - 7 } & BPS & & BPS & True & & BPS & True \\
\hline$\kappa_{c, u_{1}}$ & $-0.14(0.07)$ & & -0.02 & 0.01 & & $-0.02(0.009)$ & $0.01(0.002)$ \\
$\kappa_{c, u_{2}}$ & $-0.04(0.07)$ & & 0.02 & 0.01 & & $0.02(0.012)$ & $0.01(0.002)$ \\
$\kappa_{c, v_{1}}$ & $0.32(0.05)$ & & 0.42 & 0.35 & & $0.42(0.018)$ & $0.34(0.007)$ \\
$\kappa_{c, v_{2}}$ & $0.19(0.03)$ & & 0.22 & 0.18 & & $0.22(0.014)$ & $0.19(0.007)$ \\
$\kappa_{y_{1}, u_{1}}$ & $1.58(0.16)$ & & 1.47 & 1.44 & & $1.47(0.008)$ & $1.44(0.003)$ \\
$\kappa_{y_{1}, u_{2}}$ & $0.11(0.06)$ & & -0.03 & -0.05 & & $-0.03(0.008)$ & $-0.05(0.004)$ \\
$\kappa_{y_{1}, v_{1}}$ & $0.92(0.08)$ & & 1.10 & 1.16 & & $1.11(0.016)$ & $1.16(0.008)$ \\
$\kappa_{y_{1}, v_{2}}$ & $-0.22(0.04)$ & & -0.20 & -0.19 & & $-0.20(0.015)$ & $-0.19(0.008)$ \\
$\kappa_{y_{2}, u_{1}}$ & $0.17(0.11)$ & & -0.10 & -0.12 & & $-0.10(0.012)$ & $-0.12(0.006)$ \\
$\kappa_{y_{2}, u_{2}}$ & $1.88(0.23)$ & & 1.76 & 1.76 & & $1.76(0.042)$ & $1.75(0.009)$ \\
$\kappa_{y_{2}, v_{1}}$ & $-0.75(0.14)$ & & -0.62 & -0.51 & & $-0.61(0.032)$ & $-0.51(0.013)$ \\
$\kappa_{y_{2}, v_{2}}$ & $1.42(0.08)$ & & 1.53 & 1.46 & & $1.52(0.025)$ & $1.45(0.012)$ \\
\hline
\end{tabular}

Notes: The numbers inside parentheses are standard errors: for "Data BPS", they are estimated by BPS using a data set with 10479 household-year observations; For "Model (Small Sample)", they are computed based on 100 independent modelsimulated samples, each of which has 10500 household-year observations. Only households aged 30-57 are included.

\section{The BPS Method in This Paper}

\section{D.1 Formulas for the Transmission Coefficients}

We follow closely the approximation method proposed by Blundell, Pistaferri, and Saporta-Eksten (2016) (BPS) and try to use notations consistent with the original paper. Here we only report the formulas we use for the transmission coefficients, and the details of the derivation are available in Online Appendix 1 of BPS.

As in BPS, the wage of earner $j$ in household $i$ at age $t$ is determined by

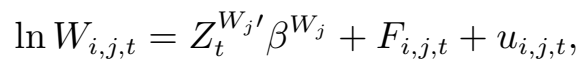

where $Z_{t}^{W_{j}}$ is a group of observable characteristics affecting wages such as age, and

$$
F_{i, j, t}=F_{i, j, t-1}+v_{i, j, t} .
$$

This implies

$$
\Delta \ln W_{i, j, t}-\Delta Z_{t}^{W_{j^{\prime}}} \beta^{W_{j}}=\Delta u_{i, j, t}+v_{i, j, t} .
$$

Define $\Delta w_{i, j, t}$ as the unexpected growth of wage that is not explained by the ob- 
servables, i.e.,

$$
\Delta w_{i, j, t}=\Delta u_{i, j, t}+v_{i, j, t} .
$$

For simplicity, we omit the household index $i$ and write it as $\Delta w_{j, t}$. Similarly, we can define unexpected the growth of consumption, labor supply, and labor income as $\Delta c_{t}, \Delta h_{j, t}$, and $\Delta y_{j, t}$.

Assuming that the after-tax income $\widetilde{T}(Y)$ is given by $(1-\chi) Y^{1-\mu}$, BPS show that by log-inearizing the first-order conditions and the budget constraints of the two-earner household problem, we have

$$
\left[\begin{array}{c}
\Delta c_{t} \\
\Delta y_{1, t} \\
\Delta y_{2, t}
\end{array}\right]=\left[\begin{array}{cccc}
\kappa_{c, u_{1}} & \kappa_{c, u_{2}} & \kappa_{c, v 1} & \kappa_{c, v_{2}} \\
\kappa_{y_{1}, u_{1}} & \kappa_{y_{1}, u_{2}} & \kappa_{y_{1}, v 1} & \kappa_{y_{1}, v_{2}} \\
\kappa_{y_{2}, u_{1}} & \kappa_{y_{2}, u_{2}} & \kappa_{y_{2}, v 1} & \kappa_{y_{2}, v_{2}}
\end{array}\right]\left[\begin{array}{c}
\Delta u_{1, t} \\
\Delta u_{2, t} \\
v_{1, t} \\
v_{2, t}
\end{array}\right]
$$

where

$$
\begin{aligned}
\kappa_{c, u_{j}} & =\psi_{c, w_{j}}, \\
\kappa_{c, v_{j}} & =\psi_{c, w_{j}}+\frac{\psi_{c, \lambda}\left[(1-\mu)\left(1-\pi_{t}\right)\left(s_{j, t}+\widetilde{\psi}_{h, w_{j}}\right)-\psi_{c, w_{j}}\right]}{\psi_{c, \lambda}-(1-\mu)\left(1-\pi_{t}\right) \widetilde{\psi}_{h, \lambda}}, \\
\kappa_{y_{j}, u_{j}} & =1+\psi_{h_{j}, w_{j}}, \\
\kappa_{y_{j}, u_{-j}} & =\psi_{h_{j}, w_{-j}}, \\
\kappa_{y_{j}, v_{j}} & =1+\psi_{h_{j}, w_{j}}+\frac{\psi_{h_{j}, \lambda}\left[(1-\mu)\left(1-\pi_{t}\right)\left(s_{j, t}+\widetilde{\psi}_{h, w_{j}}\right)-\psi_{c, w_{j}}\right]}{\psi_{c, \lambda}-(1-\mu)\left(1-\pi_{t}\right) \widetilde{\psi}_{h, \lambda}} \\
\kappa_{y_{j}, v_{-j}} & =\psi_{h_{j}, w_{-j}}+\frac{\psi_{h_{j}, \lambda}\left[(1-\mu)\left(1-\pi_{t}\right)\left(s_{-j, t}+\widetilde{\psi}_{h, w_{-j}}\right)-\psi_{c, w_{-j}}\right]}{\psi_{c, \lambda}-(1-\mu)\left(1-\pi_{t}\right) \widetilde{\psi}_{h, \lambda}}
\end{aligned}
$$

where $\pi_{t}$ is approximately the share of asset in the total discounted wealth for the household at age $t, s_{j, t}$ is approximately the share of earner $j$ 's discounted labor income in the total discounted labor income of the household, and

$$
\begin{aligned}
\widetilde{\psi}_{h, \lambda} & =\sum_{j=1}^{2} s_{j, t} \psi_{h_{j}, \lambda}, \\
\widetilde{\psi}_{h, w_{1}} & =\sum_{j=1}^{2} s_{j, t} \psi_{h_{j}, w_{1}}, \\
\widetilde{\psi}_{h, w_{2}} & =\sum_{j=1}^{2} s_{j, t} \psi_{h_{j}, w_{2}},
\end{aligned}
$$


and

$$
\begin{aligned}
& \left(\begin{array}{ccc}
\psi_{c, \lambda} & \psi_{c, w_{1}} & \psi_{c, w_{2}} \\
\psi_{h_{1}, \lambda} & \psi_{h_{1}, w_{1}} & \psi_{h_{1}, w_{2}} \\
\psi_{h_{2}, \lambda} & \psi_{h_{2}, w_{1}} & \psi_{h_{2}, w_{2}}
\end{array}\right) \\
& =\left(\begin{array}{ccc}
1 & \mu q_{1, t-1}\left(\eta_{c, w_{1}}+\eta_{c, w_{2}}\right) & \mu q_{2, t-1}\left(\eta_{c, w_{1}}+\eta_{c, w_{2}}\right) \\
0 & 1+\mu q_{1, t-1}\left(\eta_{h_{1}, w_{1}}+\eta_{h_{1}, w_{2}}\right) & \mu q_{2, t-1}\left(\eta_{h_{1}, w_{1}}+\eta_{h_{1}, w_{2}}\right) \\
0 & \mu q_{1, t-1}\left(\eta_{h_{2}, w_{1}}+\eta_{h_{2}, w_{2}}\right) & 1+\mu q_{2, t-1}\left(\eta_{h_{2}, w_{1}}+\eta_{h_{2}, w_{2}}\right)
\end{array}\right)^{-1} \\
& \times\left(\begin{array}{ccc}
-\eta_{c, p}+\eta_{c, w_{1}}+\eta_{c, w_{2}} & \eta_{c, w_{1}}-\mu q_{1, t-1}\left(\eta_{c, w_{1}}+\eta_{c, w_{2}}\right) & \eta_{c, w_{2}}-\mu q_{2, t-1}\left(\eta_{c, w_{1}}+\eta_{c, w_{2}}\right) \\
\eta_{h_{1}, p}+\eta_{h_{1}, w_{1}}+\eta_{h_{1}, w_{2}} & \eta_{h_{1}, w_{1}}-\mu q_{1, t-1}\left(\eta_{h_{1}, w_{1}}+\eta_{h_{1}, w_{2}}\right) & \eta_{h_{1}, w_{2}}-\mu q_{2, t-1}\left(\eta_{h_{1}, w_{1}}+\eta_{h_{1}, w_{2}}\right) \\
\eta_{h_{2}, p}+\eta_{h_{2}, w_{1}}+\eta_{h_{2}, w_{2}} & \eta_{h_{2}, w_{1}}-\mu q_{1, t-1}\left(\eta_{h_{2}, w_{1}}+\eta_{h_{2}, w_{2}}\right) & \eta_{h_{2}, w_{2}}-\mu q_{2, t-1}\left(\eta_{h_{2}, w_{1}}+\eta_{h_{2}, w_{2}}\right)
\end{array}\right)
\end{aligned}
$$

where $q_{j, t-1}=Y_{j, t-1} / Y_{t-1}$ is the share of labor income from the earner $j$ at age $t-1$.

The formulas when the separable preference assumption is imposed can be obtained by assuming the values of all the cross Frisch elasticities to be zero. To estimate the outside insurance coefficient $\beta$, one only needs to multiply all the $\left(1-\pi_{t}\right)$ in the formulas by $(1-\beta)$.

When taking into account the social security system explicitly, we define the human wealth as the sum of the discounted after-payroll-tax labor income and the discounted retirement benefits, and multiply all the $\left(1-\pi_{t}\right)$ in the formulas for $\kappa$ by one minus the share of retirement benefits in human wealth.

\section{D.2 Estimation}

The estimation method in this paper follows the empirical strategy in the original BPS paper. To apply the method, we first need the data on the unexpected wage growth $\Delta w_{j, t}$, unexpected consumption growth $\Delta c_{t}$, and unexpected labor income growth $\Delta y_{j, t}$ at household level. These can be obtained by regressing the log-differences of the corresponding variables on observable characteristics and constructing the residuals, i.e.,

$$
\Delta \log X_{t}=Z \hat{\beta}+\Delta x_{t},
$$

where $Z$ represents the observable characteristics, and $\hat{\beta}$ is the estimated coefficients. For the simulated data, because all the households are ex ante identical, $Z$ contains only a group of age dummies. 


\section{D.2.1 Wage Covariances}

From the wage process, we know

$$
\Delta w_{j, t}=\Delta u_{j, t}+v_{j, t} .
$$

Following BPS, we estimate the six wage process parameters, $\sigma_{u_{1}}^{2}, \sigma_{u_{2}}^{2}, \sigma_{u_{1}, u_{2}}$, $\sigma_{v_{1}}^{2}, \sigma_{v_{2}}^{2}$, and $\sigma_{v_{1}, v_{2}}$, by GMM with an identity weighting matrix using 7 moment conditions: $E\left[\Delta w_{1, t}^{2}\right], E\left[\Delta w_{2, t}^{2}\right], E\left[\Delta w_{1, t} \Delta w_{2, t}\right], E\left[\Delta w_{1, t} \Delta w_{1, t-1}\right], E\left[\Delta w_{2, t} \Delta w_{2, t-1}\right]$, $E\left[\Delta w_{1, t} \Delta w_{2, t-1}\right]$, and $E\left[\Delta w_{2, t} \Delta w_{1, t-1}\right]$. This step requires only wage data.

\section{D.2.2 Smoothing Parameters}

The smoothing parameters $\pi_{t}$ and $s_{j, t}$ are calculated directly from the data. The human wealth of household at age $t$ is calculated as

$$
\text { Human Wealth } h_{t}=(1-\chi) Y_{t}^{1-\mu}+E_{t} \Sigma_{k=1}^{R-t} \frac{(1-\chi) Y_{t+k}^{1-\mu}}{(1+r)^{k}} .
$$

Note that the expected future income levels should technically depend on the current states of the households. However, in practice, it is difficult to calculate such conditional expectations exactly, so following BPS, the expected future income levels are only conditional on characteristics that either do not change over time (e.g. education) or change in a perfectly forecastable way (e.g. age).

The smoothing parameter $\pi_{t}$ is then

$$
\pi_{t}=\frac{\text { Assets }_{t}}{\text { Assets }_{t}+\text { Human Wealth }} \text {. }
$$

And $s_{j, t}$ is simply

$$
s_{j, t}=\frac{\text { Human Wealth }}{j, t} .
$$

To be exact, the human wealth here should be the discounted after-tax labor income of each member, but with non-linear income tax at the household level, it is unclear how to divide the tax between the two members. Therefore, when calculating $s_{j, t}$, we use before-tax labor income of each member.

\section{D.2.3 Frisch Elasticities and Outside Insurance}

For the Frisch elasticities and the "outside insurance" coefficient, we follow BPS and use the 31 moment conditions in Figure 8 of the original BPS paper (and Table 1 of the BPS online Appendix) to conduct a GMM estimation with an identity weighting matrix. The moment conditions include a set of second-order moments 
of $\Delta c_{t}, \Delta y_{j, t}, \Delta w_{j, t}$, and the lag of them. The formulas for these moment conditions are derived based on the BPS formulas for $\Delta c_{t}, \Delta y_{j, t}$ and $\Delta w_{j, t}$. For example,

$$
\begin{aligned}
& E\left(\Delta c_{t}^{2}\right)=E\left[\left(\kappa_{c, u_{1}} \Delta u_{1, t}+\kappa_{c, u_{2}} \Delta u_{2, t}+\kappa_{c, v_{1}} v_{1, t}+\kappa_{c, v_{2}} v_{2, t}\right)^{2}\right] \\
& =E\left[\kappa_{c, u 1}^{2}\left(2 \sigma_{u_{1}}^{2}\right)+\kappa_{c, u_{2}}^{2}\left(2 \sigma_{u_{2}}^{2}\right)+2\left(\kappa_{c, u 1} \kappa_{c, u 2}\right)\left(2 \sigma_{u_{1} u_{2}}\right)\right. \\
& \left.+\kappa_{c, v 1}^{2}\left(\sigma_{v_{1}}^{2}\right)+\kappa_{c, v_{2}}^{2} E\left(\sigma_{v_{2}}^{2}\right)+2\left(\kappa_{c, v 1} \kappa_{c, v 2}\right)\left(\sigma_{v_{1} v_{2}}\right)\right] \\
& =p \lim \frac{1}{N T} \sum_{i=1}^{N} \sum_{t=1}^{T}\left\{\kappa_{c, u 1}^{2}(i, t)\left(2 \sigma_{u_{1}}^{2}\right)+\kappa_{c, u_{2}}^{2}(i, t)\left(2 \sigma_{u_{2}}^{2}\right)+2\left[\kappa_{c, u 1}(i, t) \kappa_{c, u 2}(i, t)\right]\left(2 \sigma_{u_{1} u_{2}}\right)\right. \\
& \left.+\kappa_{c, v 1}^{2}(i, t)\left(\sigma_{v_{1}}^{2}\right)+\kappa_{c, v_{2}}^{2}(i, t)\left(\sigma_{v_{2}}^{2}\right)+2\left[\kappa_{c, v 1}(i, t) \kappa_{c, v 2}(i, t)\right]\left(\sigma_{v_{1} v_{2}}\right)\right\} .
\end{aligned}
$$

The results for other moment conditions can be derived in a similar way. We also impose the symmetry assumptions $\eta_{h_{j}, p}=-\eta_{c, w_{j}} \frac{1}{(1-\chi)(1-\mu) Y^{-\mu}} \frac{p c}{w_{j} h_{j}}, j=1,2$, and $\eta_{h_{2}, w_{1}}=\eta_{h_{1}, w_{2}} \frac{w_{1} h_{1}}{w_{2} h_{2}}$ as the original BPS paper.

\section{D.2.4 Transmission Coefficients}

Collecting the estimation results from previous steps, the transmission coefficients for each household at each age are calculated using the formulas in Appendix D.1. The reported transmission coefficients are the sample averages of them.

\section{E Supplementary Results For Non-separable Prefer- ences}

This section reports the calibration of the model with non-separable preferences and presents all the figures and tables for the model with non-separable preferences that are not included in the main text, each of which corresponds to one figure or table for the benchmark model with additively separable preferences.

\section{E.1 Parameters for Non-separable Preferences}

With non-separable preferences, Frisch elasticities are no longer deep parameters. Given the functional form in this paper, we are able to derive the Frisch elasticities as functions of preference parameters and allocations. The formulas are shown in Appendix F. The preference parameters are then calibrated jointly to match the Frisch elasticities estimated by BPS in the absence of the separability assumption, and average hours worked by males and females in the BPS data. The parameters $\gamma, \theta$ and $\sigma$ mainly affect the Frisch elasticities, whereas the parameters 
$\alpha$ and $\xi$ mainly affect labor supply. In particular, for a given set of parameters, the model is first solved and a panel of household data are simulated. Then, based on the simulated data and the formulas for Frisch elasticities, the sample averages of Frisch elasticities and labor supply are calculated and compared with the calibration targets. $^{40}$

For the non-separable preferences, we add an additional parameter $\Psi$, which is a constant that scales the marginal utility of consumption after retirement. $\Psi$ is chosen such that the age profile of consumption is smooth at retirement. Consumption typically falls upon retirement in the data, but the literature on the retirement consumption puzzle shows that it is mainly due to work-related consumption expenditures not modeled here. ${ }^{41}$

The values of calibrated parameters of the model with non-separable preferences and the implied Frisch elasticities are summarized in Tables 13 and 14. The moments matched in calibration and their values from data are in Table 15.

\footnotetext{
${ }^{40}$ Note that, given the functional form of the utility function, there are not enough degrees of freedom to match all Frisch elasticities perfectly, and we focus on matching the upper triangular part of the matrix of Frisch elasticities, in particular, $\eta_{c, p}, \eta_{c, w_{1}}, \eta_{c, w_{2}}, \eta_{h_{1}, w_{1}}, \eta_{h_{1}, w_{2}}$ and $\eta_{h_{2}, w_{2}}$. In fact, there might be no utility function that can match exactly all Frisch elasticities estimated by BPS, due to the theoretical restrictions between Frisch elasticities imposed by their definitions. In the calibration of the non-separable utility function we then need to choose between a good fit of own-price elasticities $\left(\eta_{c, p}, \eta_{h_{1}, w_{1}}\right.$ and $\left.\eta_{h_{2}, w_{2}}\right)$ and cross-elasticities $\left(\eta_{c, w_{1}}, \eta_{c, w_{2}}\right.$ and $\left.\eta_{h_{1}, w_{2}}\right)$. The chosen parameterization is a compromise between both.

${ }^{41}$ See Hurst (2008) for a survey of this literature.
} 
Table 13: Calibrated Model Parameters

(Non-separable Preferences)

\begin{tabular}{clc}
\hline Parameter & Governing & Value \\
\hline A. Preferences & \\
$\delta$ & discount rate of utility & $1.006 \times 10^{-2}$ \\
$\alpha$ & weight of consumption & 0.124 \\
$\xi$ & weight of male labor supply & 0.413 \\
$\sigma$ & consumption Frisch elasticity & 2.24 \\
$\gamma$ & substitution between consumption and leisure & -3.00 \\
$\theta$ & substitution between male and female labor supply & 3.00 \\
$\Psi$ & consumption level after retirement & 0.695 \\
$f$ & fixed utility cost of female participation & 0.0155 \\
B. Wage Process & \\
$e^{g_{2, t}-g_{1, t}}$ & female-male wage trend ratio & 0.499 \\
C. Financial Market & \\
\multicolumn{2}{c}{ b } & borrowing constraints
\end{tabular}

Notes: This table reports the values of parameters in the model with non-separable preferences that are different from the benchmark model with additively separable preferences. Parameters not included in this table share the same values as in the benchmark model.

Table 14: Calibrated Frisch Elasticities

(Non-separable Preferences)

\begin{tabular}{lcc}
\hline & Data BPS & Model True \\
\hline$\eta_{c, p}$ & $0.417(0.122)$ & 0.413 \\
$\eta_{c, w_{1}}$ & $-0.162(0.074)$ & -0.220 \\
$\eta_{c, w_{2}}$ & $-0.050(0.077)$ & -0.094 \\
$\eta_{h_{1}, p}$ & $0.126(0.057)$ & 0.326 \\
$\eta_{h_{1}, w_{1}}$ & $0.681(0.189)$ & 0.940 \\
$\eta_{h_{1}, w_{2}}$ & $0.159(0.071)$ & 0.188 \\
$\eta_{h_{2}, p}$ & $0.079(0.121)$ & 0.326 \\
$\eta_{h_{2}, w_{1}}$ & $0.325(0.140)$ & 0.440 \\
$\eta_{h_{2}, w_{2}}$ & $0.958(0.267)$ & 0.688 \\
\hline
\end{tabular}

Notes: The numbers inside parentheses are standard errors from BPS. Only households aged 30-57 are included. 
Table 15: Empirical Targets Matched

(Non-separable Preferences)

\begin{tabular}{lcc}
\hline Empirical Targets & Data & Model \\
\hline average male labor income & 1 & 1.000 \\
average female labor income $\mid$ work & 0.491 & 0.490 \\
female-male ratio of average labor supply $\mid$ work & 0.733 & 0.734 \\
average female non-participation rate & 0.20 & 0.200 \\
average net worth & 4.188 & 4.190 \\
median debt-to-income ratio $\mid$ debt (age 21-30) & 0.163 & 0.163
\end{tabular}

Notes: This table reports the empirical moments matched by the model with non-separable preferences. Moments are for age 30-57 households unless specified otherwise. 


\section{E.2 Life Cycle Profiles}
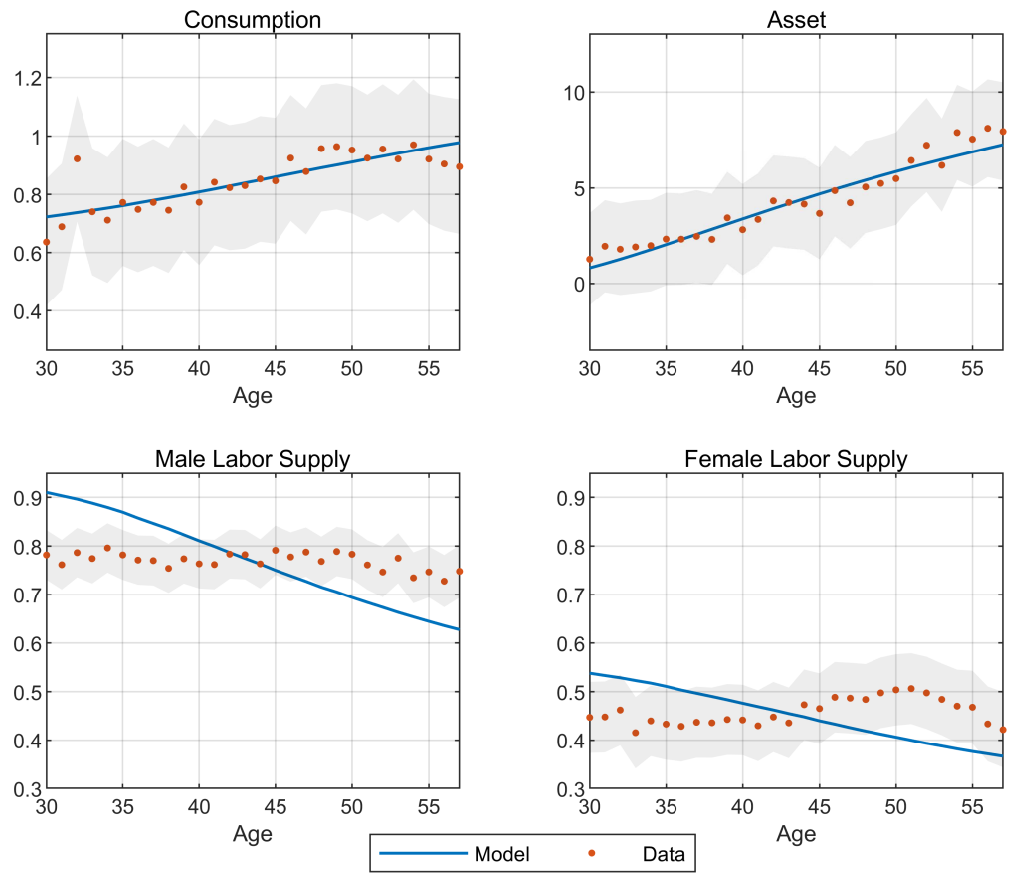

Figure 11: Life Cycles of Cross-sectional Means

(Non-separable Preferences)

Notes: This figure shows the life cycles of cross-sectional means in the model with non-separable preferences (solid lines) and in the data (dotted lines) together with the $95 \%$ confidence interval (grey bands). The data are from the BPS data set including age 30-57 households. The consumption life cycle from the data is scaled up to match the life-cycle average of consumption in the model. (Note that due to the normalization choice, the unit of labor supply here is different from that in the benchmark model.) 


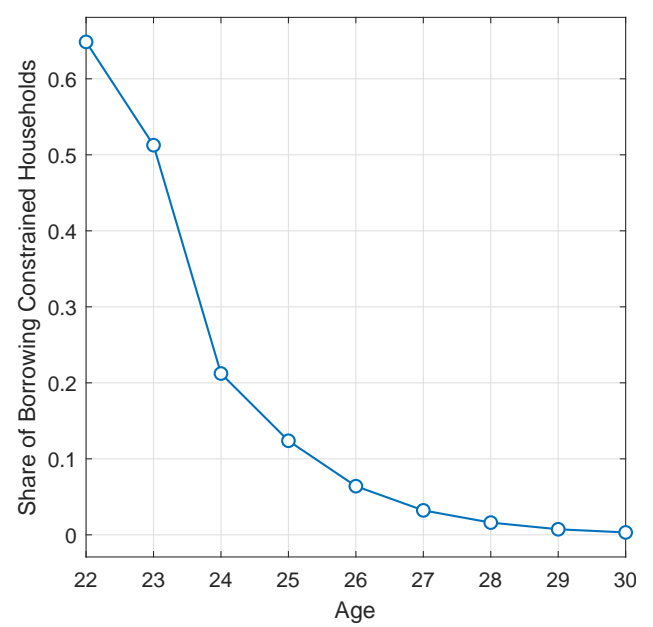

Figure 12: Share of Borrowing Constrained Households (Non-separable Preferences)

Notes: This figure plots the share of young households on the borrowing constraints in the model with non-separable preferences. 

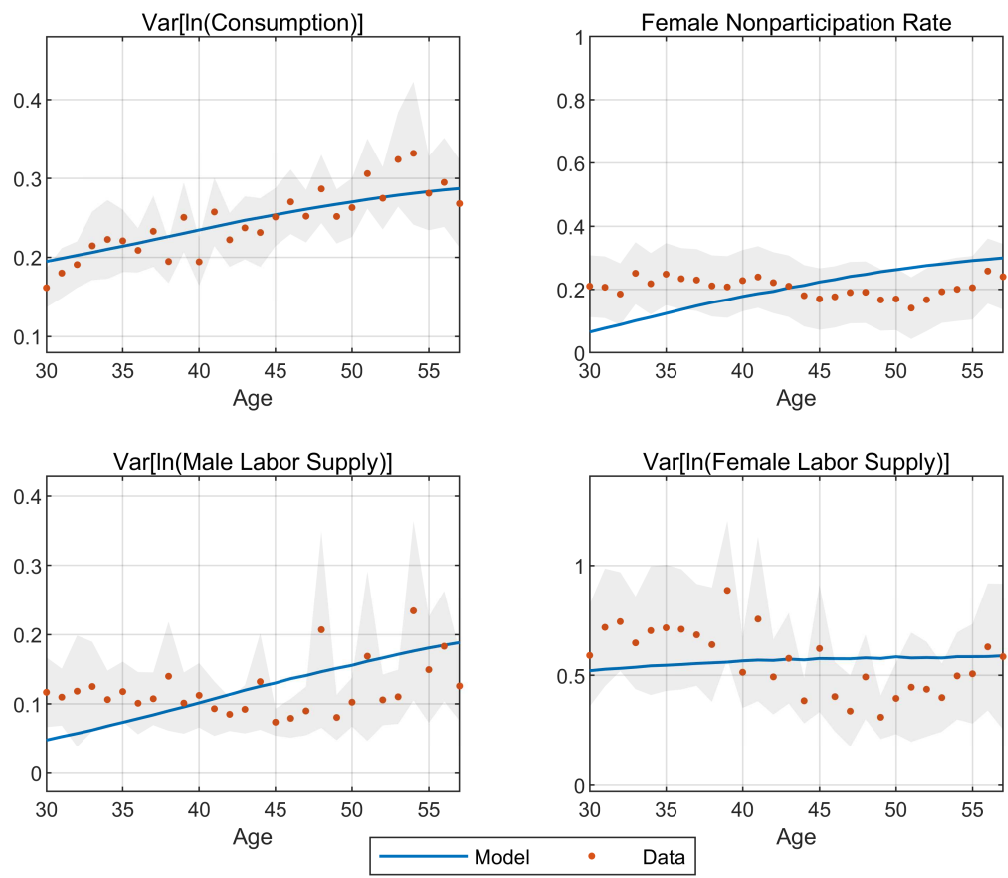

Figure 13: Life Cycles of Cross-sectional Variances and Female Non-participation (Non-separable Preferences)

Notes: This figure shows the life cycles of cross-sectional variances and female non-participation rate in the model with non-separable preferences (solid lines) and in the data (dotted lines) together with the $95 \%$ confidence interval (grey bands). The data are from the BPS data set including age 3057 households. The life cycles of variances in the model are shifted to match the life-cycle averages of variances in the data. 


\section{E.3 Age Profiles of Consumption Insurance}
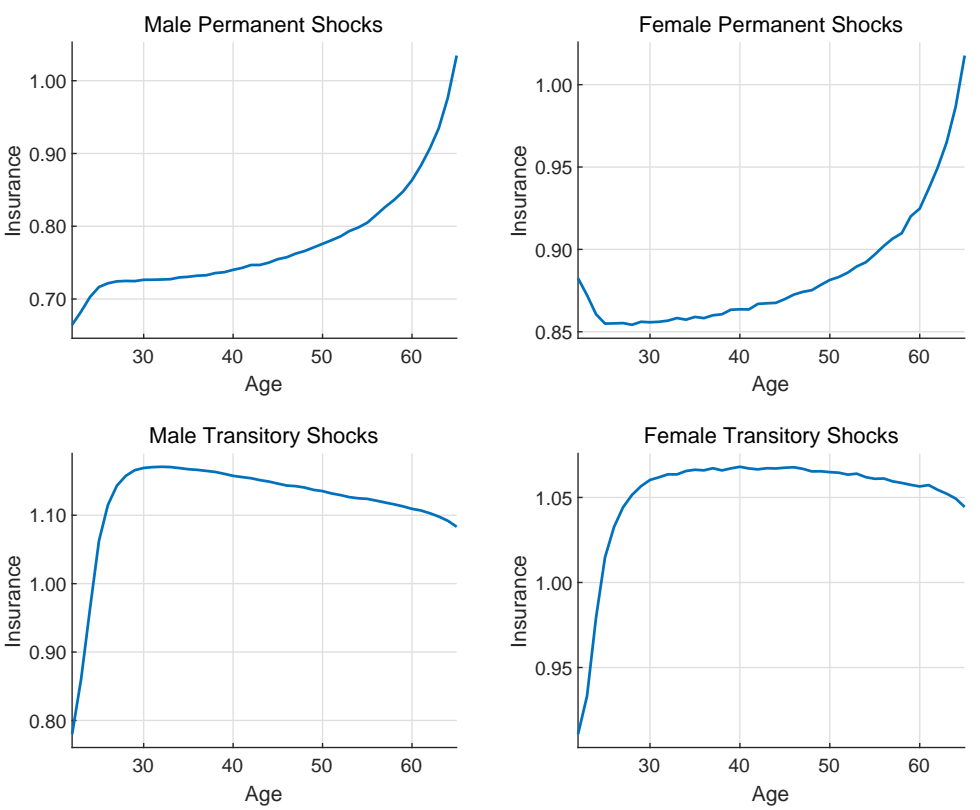

Figure 14: Age Profiles of Consumption Insurance (Non-separable Preferences)

Notes: This figure plots consumption insurance over the life cycle against male (left) and female (right) permanent (top) and transitory (bottom) wage shocks in the model with non-separable preferences.

\section{E.4 Performance of the BPS Method}


Table 16: Estimation of Transmission Coefficients (Non-separable Preferences)

\begin{tabular}{ccccc}
\hline & Model & \multicolumn{3}{c}{ Model BPS } \\
\cline { 3 - 5 } & True & Baseline $^{\mathrm{a}}$ & $\mathrm{SS}^{\mathrm{b}}$ & Outside $^{\mathrm{c}}$ \\
\hline$\kappa_{c, u_{1}}$ & -0.15 & -0.16 & -0.16 & -0.15 \\
$\kappa_{c, u_{2}}$ & -0.07 & -0.07 & -0.07 & -0.07 \\
$\kappa_{c, v_{1}}$ & 0.24 & 0.32 & 0.29 & 0.27 \\
$\kappa_{c, v_{2}}$ & 0.13 & 0.14 & 0.12 & 0.11 \\
$\kappa_{y_{1}, u_{1}}$ & 1.70 & 1.73 & 1.72 & 1.72 \\
$\kappa_{y_{1}, u_{2}}$ & 0.09 & 0.10 & 0.10 & 0.10 \\
$\kappa_{y_{1}, v_{1}}$ & 0.98 & 0.91 & 0.94 & 0.95 \\
$\kappa_{y_{1}, v_{2}}$ & -0.27 & -0.26 & -0.25 & -0.25 \\
$\kappa_{y_{2}, u_{1}}$ & 0.18 & 0.19 & 0.19 & 0.19 \\
$\kappa_{y_{2}, u_{2}}$ & 1.62 & 1.59 & 1.59 & 1.59 \\
$\kappa_{y_{2}, v_{1}}$ & -0.47 & -0.57 & -0.55 & -0.55 \\
$\kappa_{y_{2}, v_{2}}$ & 1.16 & 1.26 & 1.26 & 1.27 \\
\hline
\end{tabular}

Notes: Only households aged 30-57 are included. ${ }^{\text {a }}$ BPS baseline method.

${ }^{\mathrm{b}}$ Modified BPS method accounting for the social security system explicitly. $\quad{ }^{\mathrm{c}}$ BPS method allowing unspecified outside insurance. The outside insurance coefficient estimated here is $\beta=0.2218$. 
Table 17: Estimation of Frisch Elasticities (Non-separable Preferences)

\begin{tabular}{lcccc}
\hline & Model & \multicolumn{3}{c}{ Model BPS } \\
\cline { 3 - 5 } & True & Baseline $^{\mathrm{a}}$ & SS $^{\mathrm{b}}$ & Outside $^{\mathrm{a}}$ \\
\hline$\eta_{c, p}$ & 0.413 & 0.432 & 0.399 & 0.377 \\
$\eta_{c, w_{1}}$ & -0.220 & -0.213 & -0.206 & -0.202 \\
$\eta_{c, w_{2}}$ & -0.094 & -0.091 & -0.093 & -0.094 \\
$\eta_{h_{1}, p}$ & 0.326 & 0.254 & 0.246 & 0.242 \\
$\eta_{h_{1}, w_{1}}$ & 0.940 & 0.914 & 0.905 & 0.901 \\
$\eta_{h_{1}, w_{2}}$ & 0.188 & 0.177 & 0.175 & 0.174 \\
$\eta_{h_{2}, p}$ & 0.326 & 0.221 & 0.227 & 0.230 \\
$\eta_{h_{2}, w_{1}}$ & 0.440 & 0.362 & 0.357 & 0.356 \\
$\eta_{h_{2}, w_{2}}$ & 0.688 & 0.663 & 0.663 & 0.664 \\
\hline
\end{tabular}

Notes: Only households aged 30-57 are included.

${ }^{a}$ BPS baseline method.

${ }^{\mathrm{b}}$ Modified BPS method accounting for the social security system explicitly. $\quad{ }^{\mathrm{c}}$ BPS method allowing unspecified outside insurance. The outside insurance coefficient estimated here is $\beta=0.2218$.

Table 18: BPS Method in Small Samples (Non-separable Preferences)

\begin{tabular}{cccccccc}
\hline & Data & & \multicolumn{2}{c}{ Model } & & \multicolumn{2}{c}{ Model (Small Sample) } \\
\cline { 2 - 2 } \cline { 7 - 8 } \cline { 6 - 7 } & BPS & & BPS & True & & BPS & True \\
\hline$\kappa_{c, u_{1}}$ & $-0.14(0.07)$ & & -0.16 & -0.15 & & $-0.16(0.009)$ & $-0.15(0.003)$ \\
$\kappa_{c, u_{2}}$ & $-0.04(0.07)$ & & -0.07 & -0.07 & & $-0.07(0.010)$ & $-0.07(0.003)$ \\
$\kappa_{c, v_{1}}$ & $0.32(0.05)$ & & 0.32 & 0.24 & & $0.32(0.012)$ & $0.24(0.004)$ \\
$\kappa_{c, v_{2}}$ & $0.19(0.03)$ & & 0.14 & 0.13 & & $0.14(0.008)$ & $0.13(0.004)$ \\
$\kappa_{y_{1}, u_{1}}$ & $1.58(0.16)$ & & 1.73 & 1.70 & & $1.73(0.014)$ & $1.70(0.005)$ \\
$\kappa_{y_{1}, u_{2}}$ & $0.11(0.06)$ & & 0.10 & 0.09 & & $0.10(0.011)$ & $0.09(0.005)$ \\
$\kappa_{y_{1}, v_{1}}$ & $0.92(0.08)$ & & 0.91 & 0.98 & & $0.91(0.018)$ & $0.98(0.009)$ \\
$\kappa_{y_{1}, v_{2}}$ & $-0.22(0.04)$ & & -0.26 & -0.27 & & $-0.26(0.018)$ & $-0.27(0.010)$ \\
$\kappa_{y_{2}, u_{1}}$ & $0.17(0.11)$ & & 0.19 & 0.18 & & $0.19(0.016)$ & $0.18(0.006)$ \\
$\kappa_{y_{2}, u_{2}}$ & $1.88(0.23)$ & & 1.59 & 1.62 & & $1.59(0.032)$ & $1.61(0.009)$ \\
$\kappa_{y_{2}, v_{1}}$ & $-0.75(0.14)$ & & -0.57 & -0.47 & & $-0.57(0.025)$ & $-0.47(0.010)$ \\
$\kappa_{y_{2}, v_{2}}$ & $1.42(0.08)$ & & 1.26 & 1.16 & & $1.26(0.019)$ & $1.16(0.009)$ \\
\hline
\end{tabular}

Notes: The numbers inside parentheses are standard errors: for "Data BPS", they are estimated by BPS using a data set with 10479 household-year observations; For "Model (Small Sample)", they are computed based on 100 independent modelsimulated samples, each of which has 10500 household-year observations. Only households aged 30-57 are included. 


\section{E.5 Consumption Insurance Decomposition}

Table 19: Consumption Insurance Decomposition (Male Shocks) (Non-separable Preferences)

\begin{tabular}{|c|c|c|c|c|c|c|c|}
\hline \multirow[b]{3}{*}{ Economy } & \multicolumn{6}{|c|}{ Insurance Provided by } & \multirow{3}{*}{$\begin{array}{c}\text { Total } \\
\text { Insurance }\end{array}$} \\
\hline & \multirow{2}{*}{$\begin{array}{l}\text { Male } \\
\text { Earner }\end{array}$} & \multicolumn{3}{|c|}{ Female Earner } & \multirow{2}{*}{$\begin{array}{c}\text { Income } \\
\text { Tax }\end{array}$} & \multirow{2}{*}{$\begin{array}{c}\text { Savings+ } \\
\text { Social Security }\end{array}$} & \\
\hline & & Composition & Extensive & Intensive & & & \\
\hline \multicolumn{8}{|l|}{ A. Permanent Shock } \\
\hline 1-Earner, exogenous income & - & - & - & - & $13.3 \%$ & $34.7 \%$ & $48.0 \%$ \\
\hline+ male intensive margin & $18.5 \%$ & - & - & - & $10.8 \%$ & $39.4 \%$ & $68.8 \%$ \\
\hline+ female exogenous income & $8.9 \%$ & $27.7 \%$ & - & - & $8.4 \%$ & $27.9 \%$ & $72.9 \%$ \\
\hline + female extensive margin & $6.5 \%$ & $22.9 \%$ & $7.2 \%$ & - & $8.4 \%$ & $29.0 \%$ & $74.1 \%$ \\
\hline + female intensive margin & $-0.05 \%$ & $29.6 \%$ & $2.6 \%$ & $13.9 \%$ & $7.2 \%$ & $23.9 \%$ & $77.0 \%$ \\
\hline \multicolumn{8}{|l|}{ B. Transitory Shock } \\
\hline 1-Earner, exogenous income & - & - & - & - & $13.3 \%$ & $84.5 \%$ & $97.7 \%$ \\
\hline+ male intensive margin & $-74.2 \%$ & - & - & - & $23.1 \%$ & $169.7 \%$ & $118.6 \%$ \\
\hline+ female exogenous income & $-62.8 \%$ & $43.9 \%$ & - & - & $15.8 \%$ & $113.9 \%$ & $110.8 \%$ \\
\hline + female extensive margin & $-67.1 \%$ & $41.0 \%$ & $-2.0 \%$ & - & $17.0 \%$ & $124.5 \%$ & $113.3 \%$ \\
\hline + female intensive margin & $-65.6 \%$ & $48.9 \%$ & $-0.5 \%$ & $-3.8 \%$ & $16.0 \%$ & $117.1 \%$ & $112.3 \%$ \\
\hline
\end{tabular}

Notes: This table reports the decomposition results of consumption insurance against male permanent and transitory wage shocks in a sequence of economies with different sets of insurance channels available. Households aged 21-65 are included. Total Insurance $=\sum_{m}$ Insurance $(m)$. Details about the decomposition method are in Appendix A

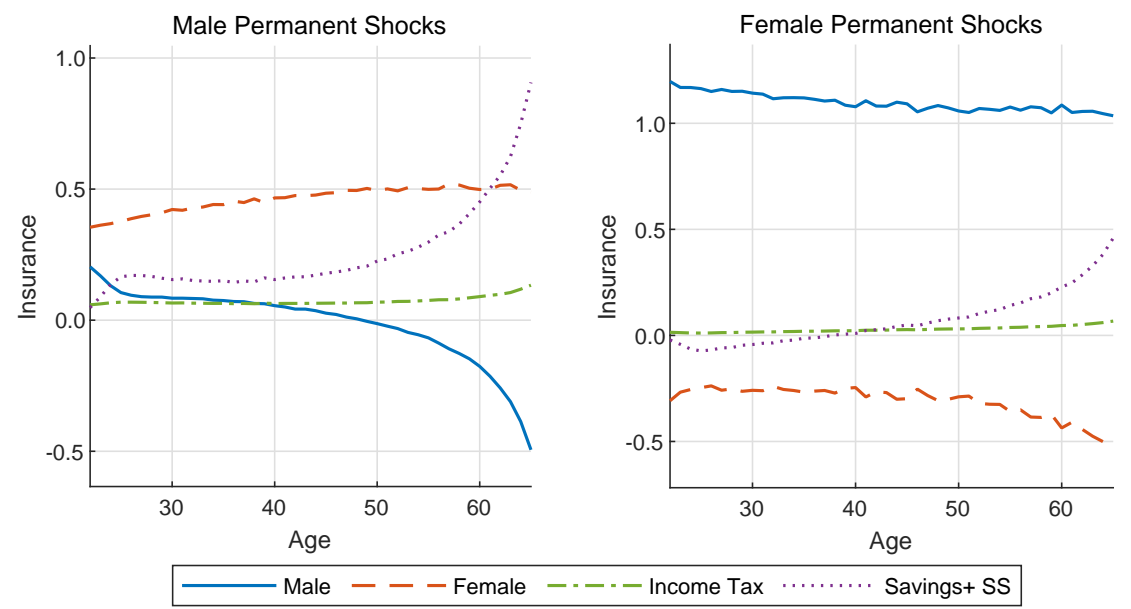

Figure 15: Age Profiles of Consumption Insurance Decomposition

(Non-separable Preferences)

Notes: This figure plots consumption insurance by source over the life cycle against male (left panel) and female (right panel) permanent wage shocks in the model with non-separable preferences. The sources are the male earner (solid line), the female earner (dash line), progressive income tax (dashdot line), and savings plus social security (dotted line). 


\section{F Frisch Elasticities for Non-separable Preferences}

In this section, we derive the formulas for the Frisch elasticities with the nonseparable preferences. They are generally functions of household allocations, i.e., they are not deep parameters. So we use the sample averages of them as the approximated true values of the Frisch elasticities, i.e., the "Model True" results.

The utility function for the non-separable preferences is

$$
u\left(C, H_{1}, H_{2}\right)=\frac{\left\{\alpha C^{\gamma}+(1-\alpha)\left[\xi H_{1}^{\theta}+(1-\xi) H_{2}^{\theta}\right]^{-\frac{\gamma}{\theta}}\right\}^{\frac{1-\sigma}{\gamma}}-1}{1-\sigma} .
$$

The intertemporal budget constraint is

$$
P C+P A^{\prime}=P(1+r) A+W_{1} H_{1}+W_{2} H_{2},
$$

where $P, W_{1}$, and $W_{2}$ are the price of the consumption good and the wages for male and female earners. From the recursive formulation of the household problem, the first-order conditions are

$$
\begin{aligned}
u_{C} & =\Delta^{\frac{1-\sigma}{\gamma}-1} \alpha C^{\gamma-1}=\lambda P, \\
u_{H_{1}} & =-\Delta^{\frac{1-\sigma}{\gamma}-1}(1-\alpha) \Gamma^{-\frac{\gamma}{\theta}-1} \xi H_{1}^{\theta-1}=-\lambda W_{1}, \\
u_{H_{2}} & =-\Delta^{\frac{1-\sigma}{\gamma}-1}(1-\alpha) \Gamma^{-\frac{\gamma}{\theta}-1}(1-\xi) H_{2}^{\theta-1}=-\lambda W_{2},
\end{aligned}
$$

where $\lambda$ is the lagrangian multiplier on the budget constraint, $\Delta \equiv \alpha C^{\gamma}+(1-$ $\alpha)\left[\xi H_{1}^{\theta}+(1-\xi) H_{2}^{\theta}\right]^{-\frac{\gamma}{\theta}}$, and $\Gamma \equiv \xi H_{1}^{\theta}+(1-\xi) H_{2}^{\theta}$. Taking log difference for both sides of these equations, we get

$$
\begin{aligned}
\left(\frac{1-\sigma}{\gamma}-1\right) d \ln \Delta+(\gamma-1) d \ln C & =d \ln \lambda+d \ln P \\
\left(\frac{1-\sigma}{\gamma}-1\right) d \ln \Delta+\left(-\frac{\gamma}{\theta}-1\right) d \ln \Gamma+(\theta-1) d \ln H_{1} & =d \ln \lambda+d \ln W_{1}, \\
\left(\frac{1-\sigma}{\gamma}-1\right) d \ln \Delta+\left(-\frac{\gamma}{\theta}-1\right) d \ln \Gamma+(\theta-1) d \ln H_{2} & =d \ln \lambda+d \ln W_{2}
\end{aligned}
$$

and

$$
\begin{aligned}
d \ln \Gamma & =\theta \mathbb{B} d \ln H_{1}+\theta(1-\mathbb{B}) d \ln H_{2}, \\
d \ln \Delta & =\gamma \mathbb{A} d \ln C-\frac{\gamma}{\theta}(1-\mathbb{A}) d \ln \Gamma \\
& =\gamma \mathbb{A} d \ln C-\gamma(1-\mathbb{A}) \mathbb{B} d \ln H_{1}-\gamma(1-\mathbb{A})(1-\mathbb{B}) d \ln H_{2},
\end{aligned}
$$

where $\mathbb{A} \equiv \frac{\alpha C^{\gamma}}{\Delta}$ and $\mathbb{B} \equiv \frac{\xi H_{1}^{\theta}}{\Gamma}$. Substitute $d \ln \Delta$ and $d \ln \Gamma$ with the formulas above, 
the system of equations becomes

$$
G \times\left[\begin{array}{c}
d \ln C \\
d \ln H_{1} \\
d \ln H_{2}
\end{array}\right]=\left[\begin{array}{c}
d \ln \lambda+d \ln P \\
d \ln \lambda+d \ln W_{1} \\
d \ln \lambda+d \ln W_{2}
\end{array}\right],
$$

where

$G=\left[\begin{array}{ccc}(\gamma-1)(1-\mathbb{A})-\sigma \mathbb{A} & (\gamma-1+\sigma)(1-\mathbb{A}) \mathbb{B} & (\gamma-1+\sigma)(1-\mathbb{A})(1-\mathbb{B}) \\ (1-\gamma-\sigma) \mathbb{A} & {[(\gamma-1+\sigma)(1-\mathbb{A})-(\gamma+\theta)] \mathbb{B}+(\theta-1)} & {[(\gamma-1+\sigma)(1-\mathbb{A})-(\gamma+\theta)](1-\mathbb{B})} \\ (1-\gamma-\sigma) \mathbb{A} & {[(\gamma-1+\sigma)(1-\mathbb{A})-(\gamma+\theta)] \mathbb{B}} & {[(\gamma-1+\sigma)(1-\mathbb{A})-(\gamma+\theta)](1-\mathbb{B})+(\theta-1)}\end{array}\right]$.

By the definition of Frisch elasticities, we have

$$
G^{-1}=\left[\begin{array}{ccc}
-\eta_{c, p} & \eta_{c, w_{1}} & \eta_{c, w_{2}} \\
\eta_{h_{1}, p} & \eta_{h_{1}, w_{1}} & \eta_{h_{1}, w_{2}} \\
\eta_{h_{2}, p} & \eta_{h_{2}, w_{1}} & \eta_{h_{2}, w_{2}}
\end{array}\right] .
$$

Note that because the values of $\mathbb{A}$ and $\mathbb{B}$ depend on the allocations chosen by households, $G$ and the Frisch elasticities all depend on the allocations and are not deep parameters.

If we want the Frisch elasticities to be deep parameters with such utility function, we must have $\mathbb{A}$ and $\mathbb{B}$ as constants. From the FOC's, this would require

$$
\begin{aligned}
\Delta^{\frac{1-\sigma}{\gamma}} \mathbb{A} & =\lambda P C, \\
\Delta^{\frac{1-\sigma}{\gamma}}(1-\mathbb{A}) \mathbb{B} & =\lambda W_{1} H_{1}, \\
\Delta^{\frac{1-\sigma}{\gamma}}(1-\mathbb{A})(1-\mathbb{B}) & =\lambda W_{2} H_{2} . \\
\frac{\mathbb{A}}{(1-\mathbb{A}) \mathbb{B}}=\frac{P C}{W_{1} H_{1}}=\text { Constant, } & =\frac{P C}{W_{2} H_{2}}=\text { Constant. }
\end{aligned}
$$

This implies the utility function needs to take the Cobb-Douglas form, i.e., $\gamma=0$ and $\theta=0$. In that case, the utility function becomes

$$
U\left(C, H_{1}, H_{2}\right)=\frac{\left[C^{\alpha}\left(H_{1}^{\xi} H_{2}^{1-\xi}\right)^{-(1-\alpha)}\right]^{1-\sigma}-1}{1-\sigma} .
$$

Follow the same method, we can derive that

$$
G=\left[\begin{array}{ccc}
\alpha-1-\alpha \sigma & (1-\sigma)(\alpha-1) \xi & (1-\sigma)(\alpha-1)(1-\xi) \\
(1-\sigma) \alpha & -\sigma(\alpha-1) \xi+(\alpha-2) \xi+(\xi-1) & -\sigma(\alpha-1)(1-\xi)+(\alpha-2)(1-\xi)+(1-\xi) \\
(1-\sigma) \alpha & -\sigma(\alpha-1) \xi+(\alpha-2) \xi+\xi & -\sigma(\alpha-1)(1-\xi)+(\alpha-2)(1-\xi)-\xi
\end{array}\right],
$$

and the Frisch elasticity matrix is just $G^{-1}$. However, the Cobb-Douglas form is not 
a good choice because it implies that the ratios between male labor income, female labor income and consumption expenditures are all constants independent of the price of consumption and wages, which is counterfactual.

\section{G Computation Method}

The household optimization problem is solved backwards using the endogenous grid method proposed by Carroll (2006). With the extensive margin of female labor supply, for each iteration and each household state, the optimization problem is solved twice under two alternative scenarios: the current period female labor supply is strictly positive or zero. The final optimal policy is obtained by comparing the discounted utility achieved in these two scenarios.

The grid for asset has 100 grid points, and the distance between two adjacent grid points increases with the asset level such that the grid points are denser around the low asset levels where borrowing constraints are more likely to bind. The range of the asset grid is age-dependent and eventually endogenously determined by the model to have a better coverage of the more relevant state space.

The joint process of the two earners' permanent wage components is approximated by a discrete Markov process with age-dependent sets of states and transition matrices, and each state corresponds to one possible realization of the two permanent components. The number of states is fixed, but the values of them vary across ages to match the unconditional dispersion of the joint distribution over the life cycle. The grid points and transition matrices are constructed in the same spirit as Tauchen (1986), and try to mimic the joint unit-root process. The grid for the two permanent components has 11 points in each dimension, so there are in total 121 grid points at each age. The discretization of the transitory components is similar and simpler. Since the transitory components are iid across ages, the grid no longer needs to be age-dependent, and no transition matrix is required. The grid for the transitory components has 5 points in each dimension, so there are in total 25 grid points. 


\section{References}

Blundell, Richard, Luigi Pistaferri, and Itay Saporta-Eksten. 2016. "Consumption Inequality and Family Labor Supply". American Economic Review 106 (2): $387-435$.

Carroll, Christopher D. 2006. "The Method of Endogenous Gridpoints for Solving Dynamic Stochastic Optimization Problems". Economics Letters 91 (3): 312 320.

Conesa, Juan Carlos, Sagiri Kitao, and Dirk Krueger. 2009. "Taxing Capital? Not a Bad Idea after All!” American Economic Review 99 (1): 25-48.

Hurst, Erik. 2008. "Understanding Consumption in Retirement: Recent Developments." In Recalibrating Retirement Spending and Saving, ed. by John Ameriks and Olivia S. Mitchell. Oxford University Press.

Rupert, Peter, and Giulio Zanella. 2015. "Revisiting Wage, Earnings, and Hours Profiles". Journal of Monetary Economics 72:114-130.

Tauchen, George. 1986. "Finite State Markov-Chain Approximations to Univariate and Vector Autoregressions". Economics Letters 20 (2): 177-181. 